\title{
Einleitung der Bandherausgeber
}

\author{
„Der Band ist stark geworden“" \\ Reimer an Schleiermacher, 30.10.1805 \\ KGA V/8, Nr. 2064, 6
}

\section{Historische Einführung 1 \\ 1. Die Vorarbeiten zur Übersetzung \\ der Dialoge Gorgias, Theaitetos, Menon und Euthydemos: a) Die Rolle Friedrich Schlegels}

Als der dritte Band der Platonübersetzungen Schleiermachers Anfang November 1805 von der Berliner Realschulbuchhandlung durch ibren Verleger Georg Reimer endgültig fertig gestellt worden war und ausgeliefert wurde, war dem Erscheinen des Bandes bereits eine lange Phase der Erarbeitung vorausgegangen, die bis fast an die Anfänge des Gesamtunternehmens zurïckreicht, das Schleiermacher zusammen mit Friedrich Schlegel 1799/1800 für den Verleger Friedrich Frommann begonnen hatte. ${ }^{2}$

F. Schlegel diskutiert in der Frühphase zunächst hauptsächlich die Herstellung der richtigen Anordnung des platonischen Euvres insgesamt; im Zuge dessen entwickelt er auch Vorstellungen zur Stellung der Dialoge dieses Bandes: Gorgias, von dessen Lektüre er bereits An-

1 Auch die Einführung zum vorliegenden Band erschließt nur die äußeren Eckdaten der Entstehung der Platonübersetzungen Schleiermachers, insbesondere der des Bandes II,1. Inhaltliche und konzeptuelle Fragen der Platondeutung oder Diskussionen über philologische Details bleiben auch hier unberücksichtigt. Für eine Behandlung ersterer ist eine Edition wie diese nicht der Ort, auf letztere ist im Sachapparat zu den jeweiligen Stellen verwiesen. Insgesamt zu vergleichen sind neben den Historischen Einführungen der Bände KGA I/3, I/4, IV/3 und IV/4 insbesondere der Briefwechsel Schleiermachers der Jahre 1799 bis 1808, erschlossen in den Bänden KGA V/3 bis V/10 mit exzellenten Indices, sowie der Briefwechsel F. Schlegels in KFSA 25 und 26 und der, Briefwechsel Schleiermachers mit Boeckh und Bekker', hrsg. von Heinrich Meisner, Mitteilungen aus dem Litteraturarchive in Berlin, Neue Folge 11, Berlin 1916.

2 Zur Vorgeschichte und zur anfänglichen Kooperation zwischen Friedrich Schlegel und Schleiermacher für eine Publikation beim Verleger Friedrich Frommann siehe ausführlich die historische Einführung zu KGA IV/3, S. XV-XXVII. 
fang 1800 berichtet, ${ }^{3}$ gehöre in die, dritte Periode und folge auf den Menon ${ }^{4}$ bzw. gehöre zwischen Theaitetos und Sophistes; ${ }^{5}$ zudem sei der Dialog unvollständig, da ihm das Proömium fehle. ${ }^{6}$ Theaitetos dagegen gehöre in die ,zweite Periode ${ }^{6} 7$ also vor den Gorgias. ${ }^{8}$ Menon und Euthydemos, dieser anfangs noch als erster Dialog der, dritten Periode vor Gorgias, ${ }^{9}$ jener als erster Dialog der, zweiten Periode geführt, ${ }^{10}$ seien schließlich gänzlich unecht. ${ }^{11}$ Kurzum: Der ,zweite Band' der gemeinsamen Übersetzung solle also Theaitetos, Gorgias,

3 Siehe den Brief von F. Schlegel, 3.2.1800, KGA V/3, Nr. 791: „Da habe ich eben den [...] Gorgias [...] gelesen und viel Betrachtungen darüber angestellt, nebenbey auch wie man ihn übersetzen soll [...]" (Z. 38-40 = KFSA 25, Nr. 38, S. 58).

4 Siehe den Brief von F. Schlegel, 8.12.1800, KGA V/4, Nr. 993: „Gorgias: Im Grunde Vernichtung der Sophisten: Sie können die Tugend nicht lehren und sind auch nicht einmal Redner" (Z. 158 f.= KA 18, S. 528). "Eine Stelle am Ende des Menon z. B. wird dann gleich zeigen, daß Gorgias auf diese folgen muß" (Z. 199 f. = KA 18, S. 529).

5 Siehe den Brief von F. Schlegel, 25.2.1802, KGA V/5, Nr. 1170: „Der Gorgias ist nothwendig zwischen Theätet und Sophistes. Ich habe ibn darauf ganz eigentlich noch einmal darauf geprüft" (Z. 58-60 = KFSA 25, Nr. 237, S. 334; vgl. Z. 50 = KFSA 25 ebenda).

6 Siehe den Brief von F. Schlegel, 25.2.1802, KGA V/5, Nr. 1170: „Am Gorgias möchte ein $\pi$ poolulov gewesen und verloren gegangen sein" $(Z .34 f .=$ KFSA 25 ebenda).

7 Siehe den Brief von F. Schlegel, 8.12.1800, KGA V/4, Nr. 993: „Theaitetos. Parallelismus zwischen der Philosophie des Parmenides und des Heraklit, des Realismus und Dualismus; und zu dem Erguß hinten noch erklärende Umdeutung des Protagoras zu einem theoretischen Dualisten" (Z. 144-147; zur Einordnung siehe besonders Z. 108. $116 \mathrm{f} .=$ KA 18, S. $527 \mathrm{f}$.).

8 Siehe den Brief von F. Schlegel, 25.2.1802, KGA V/5, Nr. 1170: „II. Theätetus, Gorgias, Sophist und Politikus" (Z. $50=$ KFSA 25, Nr. 237, S. 334).

9 Siehe den Brief von F. Schlegel, 8.12.1800, KGA V/4, Nr. 993: „Eine Stelle am Ende des Menon z. B. wird dann gleich zeigen, daß Gorgias auf diese folgen muß“ (Z. 199 f.; zur Einordnung siehe besonders Z. 157 = KA 18, S. 528 f.).

10 Siehe den Brief von F. Schlegel, 8.12.1800, KGA V/4, Nr. 993: „Euthydemos: Gegen die falsche Dialektik der Megariker, mit denen er bei seiner Zurückkunft nicht zufrieden war - da er früher wohl zur Bildung der Schule beigetragen" (Z. 128-130; zur Einordnung siehe besonders Z. $108=$ KA 18, S. 527 f.).

11 Siehe den Brief von F. Schlegel, 25.2.1802, KGA V/5, Nr. 1170: „Euthydemus und Meno können nicht von Plato sein. - So wie im lezten gelehrt wird, denkt Plato

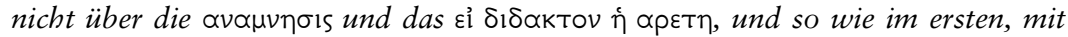
dem ohnehin die Stelle im Kratylos im Streit ist, die der Verfasser des Euthydemus eben so mißverstanden haben mag wie der des Euthyphron die Erwähnung desselben im Kratylos - kann Plato gegen die epiotische Philosophie nicht polemisirt haben, da wir in andern authentischen Werken vor Augen sehen wie er es thut" (Z. 38-45 = KFSA 25, Nr. 237, S. 334); vgl. den Brief von F. Schlegel, 4.12.1802, KGA V/6, Nr. 1400, Z. 13-16 (= KFSA 26/1, Nr. 61, S. 55). 
Sophistes, Politikos und Kratylos enthalten. ${ }^{12}$ An der Erarbeitung der Übersetzungen der Dialoge selbst ist Schlegel allerdings nicht sonderlich interessiert. Zwar willigt er zunächst - wenn auch zögerlich ein, den Gorgias selbst zu übernehmen, ${ }^{13}$ doch schließlich überläßt er Schleiermacher großzügig die Arbeit sowohl am Gorgias als auch am Theaitetos. ${ }^{14}$ Menon und Euthydemos werden auf unbestimmte Zeit verschoben, ${ }^{15}$ bis Schlegel schließlich ganz aus dem Unternebmen ausscheidet. ${ }^{16}$ Schleiermachers Auseinandersetzungen mit Schlegel, die schließlich zum Bruch führen, betreffen die Dialoge des vorliegenden Bandes eher am Rande. Vor allem die von Schlegel ab Anfang 1802 vehement behauptete Unechtheit des Menon und des Euthydemos, schließlich auch des Gorgias, akzeptierte Schleiermacher nicht. ${ }^{17}$

12 Siehe den Brief von F. Schlegel, 12.4.1802, KGA V/5, Nr. 1206: „In [den] 2ten Band kämen also - Theätetos, Gorgias, Sophistes, Politikus und Kratylos" (Z. 40 f. = KFSA 25, Nr. 253, S. 354).

13 Siehe den Brief von F. Schlegel, 22.5.1802, KGA V/5, Nr. 1236: „Da Frommann sehr zu wünschen scheint, daß ein Dialog auch von mir sei, so wollen wir für jetzt wenigstens den Gorgias auf meinen Theil rechnen. Sobald aber nur der geringste Zweifel eintritt, ob ich ibn zur bestimmten Zeit liefern kann, so melde ichs gleich, und nehme für diesen Fall Dein Anerbieten an" (Z. 14-19 f. = KFSA 25, Nr. 263, S. 364); vgl. den Brief von F. Frommann, 21.5.1802, KGA V/5, Nr. 1234, Z. 47-50.

14 Siehe den Brief von F. Schlegel, 16.11.1801, KGA V/5, Nr. 1122: „Du hast keine rechte Lust zum Phaedon; da schlage ich Dir denn gleich den Theätetus vor, der in jeder Rücksicht Dir zukömmt. [...] Möchtest Du nun doch mit dem Protagoras fertig sein und gleich rüstig an den Theätet gehn! Das würde mein Herz gar sehr erfreuen" (Z. 24-34 = KFSA 25, Nr. 203, S. 307) sowie den Brief von F. Schlegel, 12.4.1802, KGA V/5, Nr. 1206: „Wolltest Du auch noch den Gorgias nehmen, oder soll ich ihn behalten?" (Z. 41 f. = KFSA 25, Nr. 253, S. 354).

15 Siehe den Brief von F. Schlegel, 16.11.1801, KGA V/5, Nr. 1122: „Der Euthydem kömmt noch nicht so bald; es ist natürlich, daß Du auf ihn ein besondres Augenmerk hast" (Z. 25-27 = KFSA 25, Nr. 203, S. 307).

16 Siehe den Brief von F. Schlegel, 5.5.1803, KGA V/6, Nr. 1490: „Mein Vorschlag ist also [...] daß Du die Uebersetzung ganz übernimmst und ganz nach Deinem Sinne vollendest" (Z. 57-60 = KFSA 26/1, Nr. 110, S. 105). Zu den Ereignissen, die im Einzelnen zum endgültigen Abbruch des gemeinsamen Projektes führten, siehe die ,Historische Einführung' zu KGA IV/3, S. XV-XXVII.

17 Siehe den Brief an H. Herz, 14.11.1802, KGA V/6, Nr. 1377: „[...] mit so vieler Lust ich sonst an den Plato dachte und daran arbeitete so viel Unlust erwekt er mir jetzt [...], weil ich je länger je mehr die Unzulässigkeit von vielen Schlegelschen Ansichten von Plato einsehe und fast über kein Stück von denen, welche den zweiten und dritten Band ausmachen werden mit ihm übereinstimme"(Z. 5-10), vgl. auch den Brief an F. Schlegel, 10.10.1804, KGA V/7, Nr. 1829: „Du wirst daher auch finden daß von Deinen Zweifeln gegen Symposion Gorgias Menon Euthydem mit keinem Worte die Rede sein wird, weil mir diese allerdings in die 
Aus dieser stetigen Kontroverse mit Schlegel heraus entwickelte Schleiermacher dann sein eigenes Konzept vom Aufbau des Gesamtœuvres. Die Vorstufen lassen sich gut dem vermutlich zwischen 1801 und 1803 entstandenen Manuskript „Zum Platon“ entnehmen. ${ }^{18}$ In der dort und sogar noch in der 1804 gedruckten Einleitung zum Gesamtwerk vorgeschlagenen Reihenfolge der Dialoge des vorliegenden Bandes ,Theaetet Gorgias Meno ...' mag ein letzter Reflex der Zusammenarbeit zwischen Friedrich Schlegel und Schleiermacher liegen. ${ }^{19}$ Doch auch diese Spur der alten Kooperation hat Schleiermacher mit der endgültig gewählten Reihenfolge schließlich getilgt. ${ }^{20}$

große platonische Reihe gehören" (Z. 27-30 = KFSA 26/1, Nr. 242, S. 259), und seine rückblickende Generalabrechnung mit Schlegel in dem Brief an A. Boeckh, wohl Ende April bis 18.6.1808, KGA V/10, Nr. 2701, Z. 24-173 passim, hier für den vorliegenden Band einschlägig: „Auch vertheidigte ich den Euthydem gegen ihn aus einer Stelle des Sophisten, die sich meiner Meinung nach auf ihn bezog. Schon hieraus können Sie sehen wie sich damals meine ganze Anordnung schon gebildet hatte. Ich hatte mit Heindorf den Parmenides den Theaetet, den Sophisten und einige andre Gespräche für mich gelesen und daraus sich mir alles bestimmt entwikkelt. Schlegels Gegenreden auf meine Reden zeigten mir nun, was ich zum Theil schon aus einzelnen Aeußerungen in Briefen geschlossen hatte, daß seine Ansichten sich bedeutend geändert hatten. Er verwarf nun alle kleinen Gespräche nebst dem Menon, in der Folge hat er dann auch über den Gorgias und das Symposion das Verdammungsurtheil gesprochen [...] Damals wurde es mir nun ganz deutlich daß ich an dem gemeinsamen Werke nichts würde thun können als übersezen und alle Einleitungen ihm überlassen müssen. [...] Was sonst das Einzelne betrift: so erinnere ich mich, daß als er seine große Sichtung [sic] noch nicht vorgenommen hatte er den Gorgias auf den Menon folgen ließ und beide [...] in seine dritte Periode [...] sezte" (Z. 88-101. 124-129).

18 Schleiermachers Notizen „Zum Platon" (Vermutlich 1801-1803), KGA I/3, zum Aufbau des Gesamtœuvres besonders S. 357 und 373, Notate 46. 48. 118; vgl. die Gesamteinleitung KGA IV/3, S. 56-59.

19 Schleiermachers Notizen „Zum Platon" (Vermutlich 1801-1803), KGA I/3, zur Ordnung der Dialoge des vorliegenden Bandes siehe S. 352, Notat 26: „Also Theaetet Gorgias Meno, Phaedon Sophista“ (Z. 21 f.); zum Euthydem S. 353, Notat 28; $v g l$. die Gesamteinleitung KGA IV/3, S. 58,6 f. mit S. 58,19-21, wo der Theaitetos ebenfalls noch an die Spitze des zweiten Teils gestellt ist.

20 Siehe die Einleitung zum Gorgias, in dieser Edition S. 10,19-11,5, sowie die Einleitung zum Theaitetos, hier S. 437,7-12 mit S. 446,10-15. 
2. Die Vorarbeiten zur Übersetzung

der Dialoge Gorgias, Theaitetos, Menon und Euthydemos:

b) Die Rolle Ludwig Heindorfs

Die für die Bearbeitung der Dialoge des dritten Bandes schlechthin prägende Persönlichkeit war dagegen Ludwig Friedrich Heindorf (1774-1816). ${ }^{21}$ Er stammte aus Berlin, hatte dort das Gymnasium zum Grauen Kloster besucht und anschließend - nach einer Empfehlung seines Lehrers Georg Ludwig Spalding22 - 1794 bis 1796 in Halle bei Friedrich August Wolf Philologie studiert. ${ }^{23}$ Hier muß er u. a. 1795 Wolfs Platon-Vorlesung, insbesondere über die Dialoge Alkibiades I/II, Menon, Kriton und Phaidon, gehört haben. ${ }^{24}$ Zum Abschluss seiner Studien wurde er 1796 mit der Arbeit „Specimen coniecturarum in Platonem" (gedruckt Halle 1798) promoviert. Bereits 1796 kehrte er nach Berlin zurück und wurde dort am Gymnasium zum Grauen Kloster zunächst Adjunkt und Lebrer, dann aber bereits 1797 Gymnasialprofessor für Klassische Philologie. Seit seiner Studienzeit befaßte er sich intensiv mit Platon und galt seinem akademischen Lehrer Wolf zunächst als vorzüglicher Philologe. ${ }^{25}$ Schleiermacher war wohl schon Anfang 1799 nicht nur mit ihm bekannt, sondern ihm auch persönlich zugetan. ${ }^{26}$ Spätestens seit Anfang 1801 betrieb er jedenfalls gemeinsam mit ihm intensiv zweimal wöchentlich - Platonlektüre, wobei insbesondere die Textkritik im Mittelpunkt stand. ${ }^{27}$ Was für Schleiermacher die Vorbereitung auf die Übersetzung mithilfe des Gräzisten und Platonphilologen

21 Zur Biographie vgl. KGA V/6, Historische Einführung, S. XXXV-XXXVI, Nachweise im Einzelnen ebendort.

22 Siehe Wilhelm Körte: Leben und Studien Friedr. Aug. Wolf's, des Philologen, Essen 1833, Bd. 1, S. 224. - Zur Biographie Spaldings siehe KGA V/6, S. XLIV-XLVI.

23 Siehe Friedrich August Wolf. Ein Leben in Briefen, besorgt und erläutert von Siegfried Reiter, Stuttgart 1935, Brief Nr. 182: Bd. 1, S. 210, Z. 36-38.

24 Siehe Wilhelm Körte: Leben und Studien Friedr. Aug. Wolf's, des Philologen, Essen 1833, Bd. 2, S. 210. Die Vorlesung wurde erstmals 1790, dann abermals 1795, 1800, 1801, 1802, 1804 und 1811 gehalten. Eine Mitschrift der Vorlesung 1804 unter dem Titel „Einleitung in die Platonischen Schriften, nebst Erklärung zweier Dialogen vom Prof. Wolf" von H. G. J. Cludius befindet sich in der Universitätsbibliothek Göttingen unter der Signatur: 8 Cod. Ms. philol. 35 i (auch als Digitalisat).

25 Siehe oben Anm. 23.

26 Siehe den Brief an H. Herz, 10.4.1799, KGA V/3, Nr. 620, Z. 29-34.

27 Siehe den Brief an F. Schlegel, 24.1.1801, KGA V/5, Nr. 1017: „Ich lese jezt alle Woche zwei Abende Plato mit Heindorf wobei die pünktlichste Kritik sehr heilig getrieben wird; es bekomt uns Beiden aber sehr gut. Du glaubst nicht wie der Heindorf Dich liebt." (Z. 31-33 = KFSA 25, Nr. 137, S. 224). 
Heindorf war, war für Heindorf die Vorbereitung einer eigenen (kritischen) Platonausgabe. Denn Heindorf bereitete in der Tat eine Platonausgabe vor. Wolf hatte ihn offenbar bereits im Jabr 1797 dazu ermutigt, an einer von ihm selbst zu veranstaltenden Ausgabe mitzuwirken, ${ }^{28}$ und entsprechend machte sich Heindorf, offenbar ohne dass dies mit Wolf abgesprochen war, an die Arbeit zu einer Edition. Da Wolf bereits 1782 eine deutsch kommentierte Ausgabe des Symposions vorgelegt ${ }^{29}$ und spätestens seit 1790 intensiv an den Dialogen Menon, Kriton sowie Alkibiades I/II als Gegenentwurf zu der Berliner Ausgabe von Gedike, Gottleber, Schneider und Biester gearbeitet hatte (und auch immer wieder eine eigene Ausgabe ankündigte), ${ }^{30}$ sparte Heindorf diese Dialoge aus, um dem von ihm verehrten Lehrer nicht vorzugreifen. Der erste Band seiner eigenen Platonausgabe, die im

28 Siehe den Brief L. F. Heindorfs an F. A. Wolf vom 27.6.1797: „Ihre Idee ist für mich beschämend; Ich kenne mich und weiss, wie weit ich es jemals bringen werde. Nie könnte ich den Gedanken haben, mit Ihnen vereinigt den Platon zu edieren; aber wenn Sie wollen, dass ich mit dem eifrigsten Studium mich immer an diesen meinen Liebling halten, und Ibnen meine Noten und Einfälle schicken soll; wenn Sie dann das Gute auslesen und auch hier so, wie Sie immer thaten und thun, für meinen guten Namen und mein Bestes sorgen wollen - ja dann, mein Vater, können Sie mir keinen willkommeneren, erfreuenderen Vorschlag thun. Übernehmen will ich Correctur, Durchsicht und Alles, was ich nur kann, denn außer meinem Amte will ich Ihnen und meiner Wissenschaft einzig leben!" (zitiert nach W. Körte: Leben und Studien Friedr. Aug. Wolf's, des Philologen, Essen 1833, Bd. 1, S. 225 f.).

Platons Gastmahl: Ein Dialog, hrsg. von Friedrich August Wolf, Leipzig 1782.

Platonis Dialogi IV Meno, Crito, Alcibiades uterque cum animadversionibus virorum clarissimorum Gedike, Gottleber, Schneider priorumque editorum curavit Biester, Berlin 1780, 2. Auflage 1790; Vier Dialogen des Platon. Menon, Kriton und beide Alkibiades. Uebersetzt von Friedrich Gedike, Berlin 1780. Über eben diese vier hier behandelten Dialoge hielt Wolf fortwährend seine Platon-Vorlesung (s. o. Anm. 24), auch kündigt Wolf immer wieder seine Ausgabe explizit an: s. z. B. F. A. Wolfs Brief an Johann Gottfried Herder, 24.6.1790: Friedrich August Wolf. Ein Leben in Briefen (wie Anm. 23), Nr. 72: Bd. 1, S. 91, 10-13. 19: „Zunächst kehre ich wieder auf einige Zeit bei unserm Plato ein, und habe [...] 6-8 Dialogen gewissermaßen schon zum Druck parat, darunter auch Meno und die beiden Alcib., die neuerlich von Berlin aus sehr schändlich behandelt sind. [...] (es) soll auch das Gastmahl zunächst lateinisch werden"; F. A. Wolfs Brief an Karl Friedrich Hindenburg, 4.3.1791: ebd. Nr. 79: Bd. 1, S. 98, 29: „Ich gehe izt mit einer Ausgabe dieses [sc. Menon] und einiger andern Plat. Dialogen um." Vgl. auch schon seinen Brief an Johann Heinrich Voß, 6.4.1790: ebd. Nr. 68: Bd. 1, S. 87, 23-25. 
Mai 1802 erschien, ${ }^{31}$ war dementsprechend nicht nur seinem Lehrer Wolf gewidmet, sondern begriff sich als Baustein einer gemeinsamen Gesamtausgabe, die Wolf mit den vom ihm angekündigten Dialogen fortsetzen sollte. ${ }^{32}$ Wolf reagierte zunächst durchaus freundlich auf den Heindorfschen Band. ${ }^{33}$ Später freilich zerbrach das von Heindorfs Seite persönlich geradezu devot geführte Schüler-Lehrer-Verhältnis nicht zuletzt an Wolfs Eifersucht über die wissenschaftliche Unabhängigkeit Heindorfs beim Fortgang seiner Platoneditionen, verbunden mit seinem eigenen Scheitern an der geplanten und nie realisierten Gesamtausgabe. ${ }^{34}$ In der Frühphase freilich spielten Heindorf (und

31 Platonis Dialogi Quatuor. Lysis, Charmides, Hippias Maior, Phaedrus. Annotatione perpetua illustravit Lud. Frid. Heindorf, Berlin 1802. Zur Rolle dieser Ausgabe (und ihrer mit Schleiermachers Übersetzung verbundenen Vorarbeiten) siehe das lateinische Vorwort zur Ausgabe von G. L. Spalding „Plurimum opis tulit Schleiermacherus" (S. VII) sowie KGA IV/3, S. XXX. XCII. XCIV und S. 89 Anm. 1.

32 Heindorf sandte Wolf den Band am 26.5.1802 mit einem Begleitbrief. Ebendort schreibt Heindorf an Wolf: „Ohne Ihr Wissen und Ihren Willen, mit Verzichtleistung auf Ibre Belehrung über gar viele Dinge und selbst mit der Gefahr, eine Weile vor Ihnen auf eine sonderbare Weise heimlich zu erscheinen, habe ich es gewagt, [...] diese Arbeit schon jetzt in's Publikum gehen zu lassen [...] Vier Dialogen des Plato sind nun lesbar gemacht; von fünf anderen könnten Sie, wenn Sie nur wollten, in wenigen Monaten ein Meisterstück in Erklärung und Kritik für künftige Bearbeitungen liefern! O wenn Sie nur wollten! Dann lieferte ich einmal wieder vier Dialogen mit reiferen Einsichten, als diese; so würde der Plato nach und nach aufgeschlossen. [...] Wie meinen Sie, dass ich mich freuen würde, wenn $z u$ Michaelis die vier von den Berliner Gelehrten besudelten Dialogen, nebst dem Symposium von Ibnen erschienen!" (zitiert nach W. Körte: Leben und Studien Friedr. Aug. Wolf's, des Philologen, Essen 1833, Bd. 1, S. 227-230, hier S. 227. 229 f.).

33 F. A. Wolfs Brief an Heinrich Escher, 5.6.1802: Friedrich August Wolf. Ein Leben in Briefen (wie Anm. 23), Nr. 268: Bd. 1, S. 311, 23-25.

34 Schon 1806, also kurz nach Erscheinen des zweiten Bandes der Heindorfschen Platonausgabe scheint sich das Verhältnis zwischen Wolf und Heindorf abzukühlen; vgl. den Brief von L. F. Heindorf, vor dem 19.12.1806, KGA V/9, Nr. 2361, Z. 76-99. Kurz vor dem Tod Heindorfs († 23.6.1816) veröffentlichte Wolf eine Erklärung, in der er Heindorf beschuldigt, ibn hintergangen und mit seinem unerlaubten Vorpreschen mit der eigenmächtigen Publikation seiner Platoneditionen um die Ehre der Platonausgabe gebracht zu haben; an eine Kooperation sei nie gedacht gewesen, „da ich diesen Heindorf, nach ehemaliger sicherer Bekanntschaft, auch noch seit der Erscheinung seines letzten Bandes einzelner Dialogen, blo $\beta$ zu einer untergeordneten Mitarbeit, etwa zu genauem Excerpiren von Varianten oder zur Fertigung eines tüchtigen Wort-Registers, geschickt hielt. “ (F. A. Wolf, Litterarische Analekten vorzüglich für alte Litteratur und Kunst, deren Geschichte und Methodik, Bd. 1, Berlin 1816, S. III-XXII, hier S. XI). Eine Ehrenrettung des gemeinsamen Freundes veröffentlichen unmittelbar darauf Philipp Karl Buttmann 
über ihn verdeckt Wolf) eine wichtige Rolle auch und gerade für die Übersetzungsarbeit Schleiermachers. Denn Heindorf arbeitete z. T. geradezu parallel zu Schleiermacher ${ }^{35}$ - dieser an der Edition, jener an der Übersetzung, bzw. beide gemeinsam am Verständnis des Textes, dessen Herstellung und richtiger Wiedergabe, und zwar offenbar in der Zeit zwischen Januar 1801 und Mai 1802.36 Besondere Beachtung fand dabei die Bearbeitung des Parmenides und des Theaitetos. Schleiermacher scheint die Ergebnisse eben dieser "Lesung mit Heindorf“ zum Theaitetos im erhaltenen Manuskript SN 166 festgehalten zu haben. ${ }^{37}$

Dies scheinen aber auch die einzigen Reflexe einer direkten konkreten Beschäftigung mit dem Text eines der Dialoge des dritten Bandes zu sein, während Schleiermacher noch in Berlin weilte. Das ändert sich mit seinem Wechsel auf die Stelle als Hofprediger in Stolp, die er zum 1. Juni 1802 antritt. In regem Briefkontakt arbeiten Heindorf in Berlin und Schleiermacher in Stolp offenbar intensiv Heindorf mehr an Platon, Schleiermacher mehr an der, Kritik der Moral' ${ }^{38}$

und Friedrich Schleiermacher: Über Heindorf und Wolf, Berlin 1816, jetzt in KGA I/14, S. 213-221, vgl. zum Kontext S. LXXII-LXXVIII.

35 Vgl. z. B. den Brief von L. F. Heindorf, 26.8.1802, KGA V/6, Nr. 1320: „In meiner Lektüre werde ich nun ganz den Gang nehmen, den Du nimmst, damit wir immer ganz gleiches Interesse haben, also den Gorgias und andere gewählte noch aufschieben" (Z. 115-118).

36 Vgl. oben Anm. 27 und L. F. Heindorfs Brief an F. A. Wolf, 26.5.1802: „Zwei der allerschwersten Dialogen, Theätet und Parmenides, haben ich und Schleiermacher durch gemeinschaftliche Lektüre ganz durch emendirt, so dass ich hoffe, diese in der Folge einmal so lesbar zu machen, dass selbst die tirones nicht mehr über Dunkelheit im Plato klagen dürfen" (zitiert nach W. Körte: Leben und Studien Friedr. Aug. Wolf's, des Philologen, Essen 1833, Bd. 1, S. 227-230, hier S. 229). Vgl. auch Schleiermacher an August Boeckh, wohl Ende April bis 18.6.1808: „Ich hatte mit Heindorf den Parmenides den Theaetet, den Sophisten und einige andre Gespräche für mich gelesen und daraus sich mir alles bestimmt entwikkelt." (KGA V/10, Nr. 2701, Z. 91-93). Wahrscheinlich fällt die gemeinsame Lektüre des Theaitetos ins Frühjahr 1802, auf jeden Fall aber scheint Schleiermachers Erarbeitung der Übersetzung des Protagoras im Frühjahr 1801 vorausgesetzt zu sein; vgl. z. B. unten S. 620 Spalte 2 die Note zu Theaitetos $170 e$.

37 S. u. die Handschriftenbeschreibung S. XLV.- Entsprechende ,Lesungen mit Heindorf" liegen auch z. B. für einige Dialoge des Bandes I,2 (= KGA IV/4) vor: Euthyphron (SN 160/3), Parmenides (SN 161/2), Apologie (SN 163/2), Kriton (SN 164/3).

38 Gemeint sind Schleiermachers "Grundlinien einer Kritik der Sittenlehre", Berlin 1803; s. u. S. XXIV mit Anm. 49. 
Da Heindorf angekündigt hatte, dass er den Gorgias aufschieben werde, bis Schleiermacher ihn behandelt, ${ }^{39}$ arbeitet er zunächst am Theaitetos weiter und schickt bereits ab August 1802 Bemerkungen und Fragen zu Einzelstellen im Theaitetos, allerdings auch schon eine Bemerkung zum Gorgias. ${ }^{40}$ Anfang 1803 meldet er den vorläufigen Abschluss der Arbeiten am Theaitetos und am Gorgias, ${ }^{41}$ nicht obne das pikante Detail zu erwähnen, dass er unter seinem eigenen Namen Emendationen und den Vorschlag Schleiermachers zur mathematischen Stelle im Theaitetos (147d) zur Publikation an den Herausgeber H. K. A. Eichstädt geschickt hat. ${ }^{42}$

Auch der Menon und der Euthydemos sind bereits in dieser Zeit ein Thema zwischen Heindorf und Schleiermacher. Gegen Ende Oktober berichtet Heindorf über ein, Wolfisches Heft zum Menon', das zur Zeit bei Spalding sei und das er ihm schicken wolle. ${ }^{43}$ Im November befindet sich das Heft bei Schleiermacher, ${ }^{44}$ der ein Exzerpt anfertigt, das ebenfalls erhalten ist (SN 186). ${ }^{45}$ Die Bedeutung dieses Heftes scheint - trotz Heindorfs Begeisterung von der darin enthaltenen Einleitung zum Menon - eher beschränkt. Im Wesentlichen scheint es

39 S. o. Anm. 35.

40 Siehe die Briefe von L. F. Heindorf, 26.8.1802, KGA V/6, Nr. 1320, Z. 76-87; 18.-26.10.1802, KGA V/6, Nr. 1364, Z. 91-109. 136-140; wohl Nov. 1802, KGA V/6, Nr. 1394, Z. 12-14. 57-153.

41 Siehe den Brief von L. F. Heindorf, 2.3.1803, KGA V/6, Nr. 1444: „Über den Theätet habe ich gar viel zur Erklärung zusammengebracht, so daß ich wohl jetzt einen Commentar darüber schreiben könnte, ebenso über den Gorgias, wo der Findeisen in seiner sonst höchst miserabeln Arbeit doch durch Codices viel Hülfe geschaft hat, und wo ich wohl 50 Stellen ex ingenio emendirt habe, daß nun fast gar keine Dunkelheit mehr bleibt." (Z. 87-92).

42 Siehe den Brief von L. F. Heindorf, 2.3.1803, KGA V/6, Nr. 1444: „Nach Weinachten stellte ich unsre Emendationes in Theaetetum [...] nebst Deiner Erklärung der mathematischen Stelle in eine Epistola Critica zusammen, und schickte sie dem Eichstädt [...].“ (Z. 127-130). Diese Epistola ist 1806 erschienen: s. u. S. 484 Spalte 2, Note zu Platon, Theaitetos $147 b$ mit App. S.

43 Siehe den Brief von L. F. Heindorf, 18.-26.10.1802, KGA V/6, Nr. 1364: „[...] habe ich jetzt nicht bei der Hand, und ebenso wenig das Wolfische Heft über den Meno, das Spalding hat. Daraus will ich Dir nächstens seine Erklärung schicken, die mich aber nie ganz befriedigt hat. Er geht davon aus, daß Meno ganz rudis in der Mathematik sei, folglich hier gar keine Frage aus der eigentlichen Geometrie zu suchen sei." (Z. 139-144).

44 Siehe den Brief von L. F. Heindorf, wohl November 1802, KGA V/6, Nr. 1394: „Den Aristoteles behalt nur immer auf beliebige Zeit; nicht so lange das Heft, das

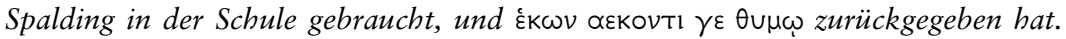
Beachte doch darin die herrliche Einleitung zum Meno, ein kleines Meisterstück historischer Kritik." (Z. 155-159).

45 S. u. die Handschriftenbeschreibung S. LIII-LIV. 
sich, wenn man das Schleiermachersche Exzerpt betrachtet (s. in dieser Edition S. 858 f. und S. 860-1041, Spalte 2 passim), seinerseits um ein mit kritischen Noten versetztes Exzerpt des Menon-Kommentars von Gedike und Biester zu handeln, vielleicht auch um eine Mitschrift (Heindorfs selbst?) von Wolfs Platon-Vorlesung von 1795.46 Zum Euthydemos meldet Heindorf Anfang März 30 Emendationen. ${ }^{47}$ Dies bedeutet, dass auch dieser Dialog gründlich von ihm bearbeitet wird.

Bis zu diesem Punkt lassen sich die Arbeiten an den vier Dialogen des dritten Bandes (II,1) als Vorarbeiten beschreiben. Schleiermacher diskutiert hauptsächlich Anordnungs- und Echtheitsfragen mit Friedrich Schlegel und liest in Berlin mit Ludwig Heindorf unter streng philologischer Rücksicht Platondialoge, schwerpunktmäßig (Parmenides und) Theaitetos. Ansonsten legt er zwischen 1800 und 1803 - zunächst in Berlin, ab Juni 1802 in Stolp - Noten „Zum Platon“ an, die zeigen, dass er sehr wohl auch die anderen Dialoge schon während dieser Zeit gelesen hat. ${ }^{48}$ In Stolp arbeitet er gleich von Anfang Juni 1802 an vor allem an der ,Kritik der Moral', die Ende August 1803 vollendet ist und schließlich unter dem Titel „Grundlinien einer Kritik der bisherigen Sittenlehre" Anfang Oktober 1803 bei Reimer in Berlin erscheint. ${ }^{49}$ Ein ganz äußerlicher Bezug auf die Beschäftigung mit Platon besteht dabei darin, dass Schleiermacher hier bereits gegen Friedrich Schlegel einige platonische Dialoge als ,echt ${ }^{\star}$ einbezieht, die dieser für unecht hält, so dass auf diese Weise die Differenzen (und

46 Vgl. die ganz ähnlich strukturierte Mitschrift von H. G. J. Cludius, zum Menon Bl. 12 ff.; s. o. Anm. 24. Im Nachlass von Friedrich August Wolf, der in der Staatsbibliothek zu Berlin - Preußischer Kulturbesitz liegt, befindet sich unter den Platonica u. a. Material zum Menon (Nr. 9, 65). Ob es sich um Vorarbeiten zu einer Edition oder Material für seine Vorlesung (oder wohl beides) handelt, bleibt offen. Vgl. auch Wilhelm Körte: Leben und Studien Friedr. Aug. Wolf's, des Philologen, Essen 1833, Bd. 2, S. 281. - Wolfs großes Interesse am Menon bezeugt auch sein Brief an Karl Friedrich Hindenburg, 4.3.1791: Friedrich August Wolf. Ein Leben in Briefen (wie Anm. 23), Nr. 79, Bd. 1, S. 98 f. Publiziert hat Wolf zum Menon jedoch nur einzelne, kurze Vorlesungen in: Vermischte Schriften und Aufsätze in lateinischer und deutscher Sprache, Halle 1802 [SB 2156], S. 112-115, Nr. XIX; S. 116-118, Nr. XX; Schleiermacher besaß sie seit dem 10. Oktober 1803 (vgl. HR 10.10.1803).

47 Siehe den Brief von L. F. Heindorf, 2.3.1803, KGA V/6, Nr. 1444, Z. 92 f.

48 KGA I/3, S. 350-353. 374: Notat 23. 24. 25. 26. 125 (zum Gorgias); S. 346. 352 f. 357. 360. 367. 373 f.: Notat 14. 26. 27. 28. 46. 59. 61. 92.118 .124 (zum Theaitetos); S. 352 f.: Notat 26 (zum Menon); S. 353. 356-358. 373: Notat 28. 40. 47. 51.119 (zum Euthydemos).

49 KGA I/4, S. 27-357 mit der Historischen Einführung S. XX-LXXI. 
letzten Endes der bevorstehende Bruch) zwischen Schlegel und Schleiermacher bereits offen zu Tage treten. ${ }^{50}$

\section{Die Fertigstellung des schließlich bei G. A. Reimer publizierten Bandes „Platons Werke II,1“ (1. Auflage, November 1805)}

Mitten in die Stolper Zeit fällt nun nicht nur der Bruch mit Friedrich Schlegel, sondern auch der Wechsel vom Verleger Friedrich Frommann zu G. A. Reimer. ${ }^{51}$ Unmittelbar nach Abschluss der ,Kritik der Moral macht sich Schleiermacher bereits ab Oktober/November 1803 an die Fertigstellung des ersten Bandes der Platonübersetzung „Platons Werke I,1 ", der dann auch im Mai 1804 erscheint. ${ }^{52}$ In rascher Folge - trotz lebhafter Reisetätigkeit - wird auch der zweite Band „Platons Werke I,2" zu großen Teilen in Stolp, teils aber auch bei Aufenthalten in Stettin, Landsberg und Berlin zügig erarbeitet. Da erreicht Schleiermacher zunächst der Ruf an die Universität Würzburg, den er ablehnt, dann der Ruf auf eine außerordentliche Professur an der Universität Halle, den er annimmt. Dort trifft er am 12. Oktober 1804 ein, und schon am 22. Oktober beginnen die Vorlesungen. Die endgültige Fertigstellung des zweiten Bandes („Platons Werke I,2“) erfolgt gleichwohl reibungslos parallel zu den akademischen Pflichten in den Monaten Oktober/November; er erscheint schließlich Ende November 1804; Schleiermacher erhält die Exemplare vor Mitte Dezember. ${ }^{53}$

Auch Heindorfs Arbeiten an seiner Edition haben inzwischen Fortschritte gemacht: Im Februar 1804 hat er zum Gorgias eine Rohfassung des Kommentars mit einem an 150 Stellen verbesserten Text fertig gestellt, kann sie aber Schleiermacher nicht überlassen, da er selbst noch am Gorgias weiter arbeitet. ${ }^{54}$ Für den Theaitetos gilt dasselbe: Hier sind 160 Stellen emendiert, und das Manuskript ist so weit fertig, dass Philipp Karl Buttmann, derzeit Professor der alten Sprachen am Joachimsthalschen Gymnasium in Berlin, ${ }^{55}$ es zur

50 Siehe den Brief an H. Herz, 14.11.1802, KGA V/6, Nr. 1377: „Öffentlich wird die Differenz auch nicht ganz verschwiegen bleiben, denn ich muß mich in der Kritik der Moral auf manches beziehen was er für unächt hält." (Z. 14-16).

51 Siehe KGA IV/3, S. XXV-XXVII.

52 Zum Entstehen des ersten Bandes $(I, 1)$ siehe KGA IV/3, S. XXVII-XXXVI.

53 Zum Entstehen des zweiten Bandes $(I, 2)$ siehe KGA IV/4, S. XV ff.

54 Siehe den Brief von L. F. Heindorf, 11.2.1804, KGA V/7, Nr. 1656, Z. 59-92; vgl. den Brief 13.3.1804, KGA V/7, Nr. 1684, Z. 22-24.

55 Zur Biographie Buttmanns siehe KGA V/8, S. XXXVII f. 
Korrektur erhalten hat. ${ }^{56}$ Vom Euthydemos ist noch nicht die Rede, Menon war ja mit Rücksicht auf Wolf ohnehin ausgespart worden. Auf jeden Fall drängt Heindorf so zum Druck seines eigenen Bandes, dass Schleiermacher das Material nicht vor Erscheinen des Bandes wird einsehen können. ${ }^{57}$

Nachdem am 22. Oktober die Vorlesungen begonnen haben, ${ }^{58}$ wendet sich Schleiermacher schon Ende Oktober dem dritten Band $(I I, 1)$ zu und beginnt Anfang November allmählich mit der Arbeit, die dann im Januar 1805 massiv einsetzt. ${ }^{59}$ Die Nachricht, dass Heindorfs zweiter Platonband beim Verleger Gottfried Carl Nauck im Druck ist, veranlaßt Schleiermacher endgültig, die konzentrierte Arbeit jetzt aufzunehmen. ${ }^{60}$ Die Hoffnungen auf die Fertigstellung der Heindorfschen Ausgabe werden jedoch dadurch getrübt, dass sich der Druck

56 Siehe den Brief von L. F. Heindorf, 13.3.1804, KGA V/7, Nr. 1684, Z. 1-10. 21 f.

57 Siehe den Brief von L. F. Heindorf, 13.3.1804, KGA V/7, Nr. 1684: „Leider wirst Du nun nicht im Stande sein, die Sachen zu den drei übrigen Dialogen vor dem Druck zu studiren." (Z. 24 f.); mit den drei übrigen Dialogen sind neben dem Gorgias wohl Theaitetos, Euthydemos und Kratylos gemeint, da Heindorf diese als Ensemble zu bearbeiten scheint: siehe den Brief von L. F. Heindorf, 11.2.1804, KGA V/7, Nr. 1656, Z. 6-9.

58 Schleiermacher bietet drei Vorlesungen an: 1) Haupt- und Fundamentallehren des Theologischen Systems, 2) Enzyklopädie und Methodologie, 3) Christliche Sittenlehre; vgl. Andreas Arndt, Wolfgang Virmond: Schleiermachers Briefwechsel (Verzeichnis) nebst einer Liste seiner Vorlesungen, Berlin / New York 1992, S. 300.

59 Siehe die Briefe an H. und E. von Willich, 30.10.1804, KGA V/8, Nr. 1841: „Hie und da kann ich nun doch ein wenig an den dritten Band des Platon denken." (Z. 57 f.) und an G. A. Reimer, 4.11.1804, KGA V/8, Nr. 1844: „Ich arbeite bisweilen schon ein wenig für den 3 ten Band des Plato, aber freilich noch will es nicht viel sagen." (Z. 32 f.); vgl. auch KGA V/8, Nr. 1878, Z. 1-5.

60 Siehe den Brief an G. A. Reimer, 14.1.1805, KGA V/8, Nr. 1898: „Zufällig habe ich Dir wol nicht gesagt, daß an der zweiten Heindorfischen Sammlung Platonischer Dialogen die sich Nauk doch nicht hat nehmen lassen schon gedrukt wird. Dies erleichtert mir die Arbeit zum nächsten Band; da 3 große Dialogen dieselben sind, gar sehr, und ich habe nun noch [viel] so große Zuversicht ihn im Sommer fertig zu machen." (Z. 44-48). Der zweite Band enthielt allerdings nur zwei Dialoge (s. u. Anm. 61): Platonis Dialogi Duo. Gorgias et Theaetetus, emendavit et annotatione instruxit Lud. Frid. Heindorfius. Accedit auctarium animadversionum Philippi Buttmanni, Berlin 1805. Schleiermacher hatte wohl auch den Euthydemos in dem Band erwartet, der allerdings erst in dem darauf folgenden Band enthalten war: Platonis Dialogi Tres. Cratylus Parmenides Euthydemus, emendavit et annotatione instruxit Lud. Frid. Heindorfius, Berlin (G. C. Nauck) 1806 (s. u. Anm. 61). 
wegen der Krankheit Heindorfs erst einmal verzögert. ${ }^{61}$ Auch der sonst stets hilfreiche Spalding steht wegen einer Italienreise nicht für die heiße Phase zur Verfügung. ${ }^{62}$ Mit F. A. Wolf, der nun in Halle sein neuer Kollege ist, kommt eine Zusammenarbeit aufgrund persönlicher Abneigung gar nicht in Frage. ${ }^{63}$ Schleiermacher ist also auf sich allein gestellt. Gleichwohl plant er die Fertigstellung des Bandes bis zum Sommer. ${ }^{64}$ Im März und April arbeitet er dann so intensiv, dass Gorgias und Theaitetos in einem ersten Durchgang fertig sind, der Euthydemos fast zur Hälfte. ${ }^{65}$ Im Mai widmet sich Schleiermacher dann dem Menon, besonders der sog. ,mathematischen Stelle und bittet Ph. K. Buttmann um Hilfe, ${ }^{66}$ die er auch gewährt. ${ }^{67}$ Auch findet

61 Siehe den Brief an G. A. Reimer, Februar 1805, KGA V/8, Nr. 1927: „Heindorfs Druk ist wie ich fürchte Krankheits wegen unterbrochen was mir auch sehr fatal ist da die beiden ersten Dialogen unseres Bandes bei ihm vorkommen." (Z. 23-25). Vgl. auch den Brief von L. F. Heindorf, 23.3.1805, KGA V/8, Nr. 1939: , Wäre der Gorgias eher fertig geworden, so hätte ich ihn Dir gewiß schon geschickt. Der Buchdrucker versprach ihn in sechs Wochen zu liefern, und nun ist über ein Vierteljahr daraus geworden, so daß mit genauer Noth noch der Theätet zur Messe fertig werden kann. Da das Buch so angeschwollen ist, so würden ohnehin alle 4 Dialogen nicht in einen Band kommen können; ich will daher nach Ostern noch einen Band fertig machen, enthaltend den Cratylus, Euthydem und Parmenides, in dem ich noch hinter unsern Arbeiten her eine kleine Nachlese gefunden habe." (Z. 28-35).

62 Siehe den Brief an G. A. Reimer, Februar 1805, KGA V/8, Nr. 1927: „Daß Spalding nach Italien reist ist doch ein garstiger Verlust für den Plato; ich muß mir nun zwei Augen mehr anschaffen." (Z. 53 f.).

63 Siehe den Brief an C. G. von Brinckmann, 15.12.1804, KGA V/8, Nr. 1880: „Wolf stößt mich doch durch seine Härte und Einseitigkeit so ab, daß nur die Ehrfurcht vor seinem Genie und seiner Virtuosität dem einigermaßen das Gegengewicht halten kann, und daß ich doch kaum das Herz haben werde ibn so wie es sein könnte und sollte für meinen Plato zu benuzen." (Z. 49-53).

64 Siehe den Brief an G. A. Reimer, Februar 1805, KGA V/8, Nr. 1927, Z. 22 f.

65 Siehe den Brief an G. A. Reimer, März/April 1805, KGA V/8, Nr. 1949: „Am Plato arbeite ich izt täglich. Allein ich kann bei diesem Bande kaum anders als zuvor die erste Bearbeitung des Ganzen fertigen ehe ich an die lezte eines einzelnen Dialogs gehe. [...] Die erste Arbeit des Gorgias und Theaetets ist fertig, auch fast der halbe Euthydem [...]" (Z. 39-43).

66 Siehe den Brief von L. F. Heindorf, wohl erste Maibälfte 1805, KGA V/8, Nr. 1963: „Deine Aufträge an Buttmann werde ich morgen mündlich besorgen. Er las mir vorgestern Deine Erklärung der Menonischen Stelle vor, die mich ebenso wenig, als ihn befriedigte, wiewohl ich sie nicht genauer prüfen konnte. Ich werde mir also Deinen Brief an ibn geben lassen. Du hast doch alle Emendationen von Wolf aus dem Hefte ehemals exerpirt? Leider liegt das Heft bei Spalding, sowie auch das Exemplar, was ich bei seinen Vorlesungen hatte, und in das andre habe ich die Emendationen nicht eingetragen, so daß ich, als Buttmann etwas über den Meno für Dich verlangte, fast gar nichts habe finden können. Denn was ich 
jetzt offenbar Schleiermachers Exzerpt des ,Wolfischen Heftes', das Heindorf Schleiermacher im November 1802 geliehen hatte, Verwendung. ${ }^{68}$ Im Mai wird auch der Druck der Heindorfschen Ausgabe des Gorgias und des Theaitetos fortgesetzt, ${ }^{69}$ Schleiermacher bittet im Juli um Zusendung des Theaitetos, ${ }^{70}$ und erhält ihn offenbar tatsächlich im August von Heindorf mit dem Angebot, bei den Korrekturen des Übersetzungsbandes zu helfen. ${ }^{71}$ Gleichzeitig kommen die Aushängebogen der Gorgiasübersetzung bei Schleiermacher an, ${ }^{72}$ Schleiermacher seinerseits schickt das endgültig fertige Manuskript des Theaitetos samt Einleitung an Reimer (für dessen Abschluss er sogar seine Vorlesungen hat ausfallen lassen). ${ }^{73}$ Anfang September fehlt noch die zweite Hälfte des Euthydemos und die Redaktion der Anmerkungen, ${ }^{74}$ Mitte September scheint auch der Euthydemos komplett, ${ }^{75}$ Ende September schließlich scheint alles inklusive aller Anmerkungen fertig zu sein. ${ }^{76}$ Das Hin und Her der Korrekturen der Aushängebogen erstreckt sich parallel zur Übersendung der letzten Manuskripte von Anfang September bis Mitte Oktober. ${ }^{77}$ Nachdem Heindorfs zweiter Platonband erschienen ist, ${ }^{78}$ übernimmt er die letzte Korrektur in Berlin und fügt selbst eine Anmerkung, ${ }^{79}$ insbesondere jedoch die Seitenverweise der Anmerkungen auf die zugehörigen Textstellen hinzu (die damit offensichtlich nicht Schleiermacher selbst vorgenom-

nachher gelegentlich in der Bipontina beigeschrieben, hat gewiß Wolf schon weggenommen." (Z. 62-72). Zum, Wolfischen Heft" und dessen Exzerpt durch Schleiermacher s. S. XXIII-XXIV.

67 Brief von Ph. K. Buttmann, 14.5.1805, KGA V/8, Nr. 1965 komplett (SN 263/1), s. u. S. $L V$.

68 S. u. die Handschriftenbeschreibung S. LIII-LIV.

69 Siehe den Brief von L. F. Heindorf, wohl erste Maihälfte 1805, KGA V/8, Nr. 1963, Z. 56-61.

70 Siehe den Brief an L. F. Heindorf, vor dem 29.7.1805, KGA V/8, Nr. *2002.

71 Siehe den Brief von L. F. Heindorf, August 1805, KGA V/8, Nr. 2010, Z. 1-3. 73-80. 129-131.

72 Siehe den Brief von G. A. Reimer, Anfang August 1805, KGA V/8, Nr. 2009.

73 Siehe den Brief an G. A. Reimer, August 1805, KGA V/8, Nr. 2011, Z. 1-7.

74 Siehe den Brief an J. C. Gaß, 6.-13.9.1805, KGA V/8, Nr. 2026, Z. 4-22.

75 Siehe den Brief an G. A. Reimer, 14.9.1805, KGA V/8, Nr. 2033, Z. 3-18. 51 f.

76 Siehe den Brief an G. A. Reimer, wohl 23.9.1805, KGA V/8, Nr. 2039, Z. 30 f.

77 Siehe die Briefe von G. A. Reimer, 7.9.1805, KGA V/8, Nr. 2027, Z. 1-14, in dichter Folge bis zum 25.10.1805, KGA V/8, Nr. 2064, Z. 1-8.

78 Siehe oben Anm. 61.

79 Siehe den Brief an G. A. Reimer, 8.10.1805, KGA V/8, Nr. 2045: „Ein Karton hatte ich noch mit Heindorf verabredet, und eine Anmerkung sollte er hinzufügen, $z u$ welchem Behuf ihm hoffentlich das Manuscript wird ausgehändigt worden sein." (Z. 40-42). 
men oder wenigstens am Ende autorisiert hat). ${ }^{\circ 0}$ Anfang November erscheint schließlich der Band „Platons Werke II,1 “, am 9.11.1805 trifft der Band bei Schleiermacher in Halle ein, freilich zu spät für die Michaelismesse. ${ }^{81}$

Schleiermachers eigene Aktivitäten scheinen durch den zügigen Abschluss des Bandes, sicher auch durch die neuen Wirkungsmöglichkeiten der frisch angetretenen Hallenser Professur, sowohl was den Fortgang der Platonübersetzung betrifft, als auch in inhaltlich-systematischer Hinsicht, nachhaltig beflügelt. Gleich mit Eintreffen der Exemplare des dritten Platon-Bandes denkt er schon an den vierten, Kratylos, Sophistes, Politikos und das Symposion enthaltend, ${ }^{82}$ die den eingeschlagenen Weg noch deutlicher bervortreten lassen sollten. ${ }^{83}$ Inhaltich entscheidend aber scheint insbesondere die TheaitetosLektüre geworden zu sein: Schleiermacher arbeitet überraschend eine

80 Siehe den Brief von G. A. Reimer, 18.9.1805, KGA V/8, Nr. 2036: „Die Correctur besorgt Heindorf einmal und der kann leicht die Seitenzablen wegen der Anmerkungen beifügen." (Z. 15-17); vgl. im Nachbinein den Brief von L. F. Heindorf, 28.12.1805, KGA V/8, Nr. 2104: „Bist Du im Ganzen mit meiner Revision der Übersetzung zufrieden oder habe ich viel errata stehen lassen? Es ging zuletzt gar $z u$ rasch. Aber Du Teufel hast mich recht gehetzt. Gegen das Ende der Noten hattest $D u d a$, wo ich die Seitenzahlen hinzufügen mußte, oft andre Worte gesetzt, als in der gedruckten Übersetzung standen, und einigemal wo die Note [für] etwas ganz allgemeines galt, habe ich alle mein bischen iudicium und Divination zusammennehmen müssen, um die richtige Seiten- und Zeilenzahl zu treffen. Das ist nur ein Monitum für die Zukunft." (Z. 179-186). Vgl. z. B. S. 735 W' Anm. 59.

81 Siehe den Brief an G. A. Reimer, 9.11.1805, KGA V/8, Nr. 2071: „Der Plato ist glüklich angelangt. Leider aber sehe ich nun daß er gewiß nicht mehr zur Messe gekommen ist. [...] Stärker ist er allerdings geworden als ich dachte. " (Z. 2 f. 7).

82 Siehe den Brief an G. A. Reimer, 9.11.1805, KGA V/8, Nr. 2071: „Stärker ist er [sc. der dritte Band II,1] allerdings geworden als ich dachte. Aber lieber Freund die noch übrigen beiden des zweiten Theils werden leicht eben so stark werden: und es geht doch nicht gut anders an. Denn für drei wäre es wieder zu wenig und drei würden auch gewiß später fertig werden als zwei. Im nächsten Bande kann ich die Einleitungen größtentheils ziemlich kurz machen, im folgenden aber geht es vielleicht weniger. Gern arbeitete ich schon jezt wieder etwas vorläufiges, wie es denn auch Noth thäte; es ist nur zu verführerisch auf Heindorf zu warten der grade am nächsten Dialog drukken läßt. Schikt er mir aber nicht bald Fortsezung so entschließe ich mich kurz und nehme unterdeß ein anderes Gespräch vor." (Z. 7-16).

83 Siehe den Brief an J. E. Th. von Willich, vor Mitte März 1806, KGA V/8, Nr. 2162: „In dem Bande des Platon den Du jezt liest stellt sich freilich das Ganze schon weit deutlicher hin und auch meine Ansicht muß nun immer klarer werden. Der Theätet vorzüglich ist ein Werk voll der hellsten Anschaunng und der tiefsten philosophischen Kunst. Ich darf an die Gespräche die ich im Kopf habe und die meiner Ethik zur Vorbereitung dienen sollten gar nicht denken wenn mir dieses berrliche Werk vorschwebt." (Z. 39-45). 
Neuausgabe der Heraklit-Fragmente aus (erschienen bei Reimer in Berlin im Museum der Alterthums-Wissenschaft, Erster Band: bibliothekarisch 1807, das dritte Stück allerdings kalendarisch erst 1808),84 die ganz offensichtlich eine Weiterfübrung der Theaitetos-Lektüre darstellt. Außerdem beginnt er, ebenfalls überraschend, bereits im Sommersemester 1805 - beginnend am 20. Mai und endend am 20. September, ${ }^{85}$ also nur kurz nach dem ersten Abschluss des Theaitetos im April und mitten in der Endredaktion im August - eine Vorlesung über Hermeneutik, deren konzeptuelle Abhängigkeit von Schleiermachers Platon-, resp. Phaidros-, Theaitetos- und Menon-Lektüre evident, aber von der Forschung noch gar nicht hinreichend erschlossen ist.

\section{Erste Reaktionen und Rezensionen}

Nach anfänglichen Schwierigkeiten bei der Versendung der Exemplare des ,feinen' Platon treffen die Bände schließlich Anfang Februar 1806 ein. ${ }^{86}$ Eine erste, kritische Reaktion erhält Schleiermacher von Spalding, der zwar neidisch auf das Erscheinen eines dritten Bandes ist, bei der Lektüre des Gorgias aber mitteilt, „dass der Ton der Übersezung [...] in Gefahr scheint, etwas zurükzuweichen von der erstangegebenen Veredelung der Sprache" ${ }^{87}$ Eine weitere frühe Reak-

84 Friedrich Schleiermacher: Herakleitos der dunkle, von Ephesos, dargestellt aus den Trümmern seines Werkes und den Zeugnissen der Alten. Museum der Alterthums-Wissenschaft, hrsg. von Friedrich August Wolf und Philipp Buttmann. Ersten Bandes Drittes und letztes Stück. Berlin, in der Realschulbuchhandlung. 1808; jetzt in KGA I/6, S. 101-241 mit S. XXV-XXXV; vgl. Lutz Käppel: (Re)Konstruktion von Antike als (Neu)Konstruktion von Moderne. Schleiermachers Auseinandersetzung mit Platon und Heraklit, in: Reformation und Moderne. Pluralität - Subjektivität - Kritik, hrsg. von J. Dierken, A. von Scheliha und S. Schmidt, Schleiermacher-Archiv Band 27, Berlin / Boston 2018, S. 699-717.

KGA I/4, S. 3-69 mit S. XIX-XXII; vgl. Andreas Arndt, Wolfgang Virmond: Schleiermachers Briefwechsel (Verzeichnis) nebst einer Liste seiner Vorlesungen, Berlin / New York 1992, S. 300.

86 Siehe die Briefe von G. A. Reimer, 26.11.1805, KGA V/8, Nr. 2082, Z. 3-6, und an G. A. Reimer, 24.1.1806, KGA V/8, Nr. 2127, Z. 12-14, und 10.2.1806, KGA V/8, Nr. 2242, Z. 23-25.

87 Siehe die Briefe von G. L. Spalding, 7.1.1806, KGA V/9, Nr. 2113a: „Den dritten Band des Plato habe ich erhalten, mit Neid gegen den, der dritte Bände liefert. Den Gorgias will ich gewiß bald lesen, mit meinen Schülern, womit das Original. Ihnen beistehen bei dem Plato, weil Sie doch Beistand von mir hoffen, das ist meine Pflicht." (Z. 66-69); 8.3. bis 15.3.1806, KGA V/8, Nr. 2159: „Im Lesen des Gorgias rükke ich vor nach und nach. Diesem zufolge sage ich Ihnen, dass der Ton 
tion kommt von Schleiermachers Freund, dem Professor für systematische und praktische Theologie in Breslau Joachim Christian Gaß,88 der Schleiermachers Werk, besonders den Gorgias und den Theaitetos, insgesamt preist, mit der leichten Ironie freilich, dass er "wohl hie und da einen zu tiefen Sinn in die Darstellungen des Platon" lege. ${ }^{89}$ Öffentliche Reaktionen auf die Publikation des Bandes sind spärlich. Noch 1816, also 12 Jahre nach Erscheinen des ersten Bandes der ersten Auflage, schreibt Schleiermacher in der Vorrede zur zweiten Auflage des Bandes I,1: „[...] theils hätte ich auch gern erst mehrere Beurtheilungen zur Hand gehabt, die mir bisher sehr sparsam vorgekommen sind; sei es daß sie diesen Arbeiten überhaupt nicht gegönnt werden, oder daß man sie gegen sonstige Sitte bei Werken von diesem Umfang bis zur Beendigung aufsparen will." 90 Dies gilt in gleicher Weise für den zweiten Band und verschärft sich noch für den dritten.

Die Suche nach gewichtigen Rezensenten hatte sich von Anfang an als kompliziert und schwierig erwiesen. Nachdem Heinrich Karl Abraham Eichstädt (1772-1848), der Herausgeber der Jenaischen Allgemeinen Zeitung, ${ }^{91}$ sich jahrelang intensiv bemüht hatte, einen Rezensenten zu finden, übernimmt schließlich Ferdinand Gotthelf Hand (1786-1851),92 die Abfassung der Rezension, die erst 1813 erscheint und alle fünf Bände des ersten und zweiten Teils berücksichtigt.

Friedrich Ast (1778-1841), ein Jenenser Schüler Eichstädts und auch Friedrich Schlegels, der seit 1802 in Jena lehrte und später dann, 1805, an die Universität Landshut berufen und 1825 mit dem Umzug

der Übersezung mir in Gefahr scheint, etwas zurükzuweichen von der erstangegebenen Veredelung der Sprache. Ungewaschen (p. 467.b) sagt der Platonische Polos wol nicht, und darf es wol nicht sagen. Úmeppuñ sind ungeheure Dinge."(Z.134-139).

88 Zur Biographie siehe KGA V/8, S. XL f.

89 Siehe den Brief von J. C. Gaß, 23.8.1806, KGA V/9, Nr. 2245: „Ich glaube aber auch, daß sich keine bedeutenden Ausstellungen dagegen machen laßen, es müßte denn die sein, daß Sie wobl hie und da einen zu tiefen Sinn in die Darstellungen des Platon legen und sie in einen genauern Zusammenhang unter einander bringen, als dieser vom Urheber selbst mag beabsichtigt sein. Ihre Einleitungen scheinen mir den Platon weiter zu führen, nicht als er selbst wollte, sondern, als er war und es vermogte." (Z. 106-112).

90 KGA IV/3, S. 10.

91 Zur Person siehe KGA V/7, S. 31; vgl. auch insgesamt Hermann Patsch: Schleiermachers Briefwechsel mit Eichstädt, in: Zeitschrift für neuere Theologiegeschichte 2, 1995, S. 255-302. Vgl. ausfübrlich KGA IV/3, S. XXXVI-XXXVIII.

92 Ferdinand Gotthelf Hand, 1807 als Schüler Gottfried Hermanns in Leipzig promoviert, ab 1817 Professor für Klassische Philologie in Jena. 
der Universität nach München versetzt wurde, ${ }^{93}$ publiziert schon 1808 in dichter Folge Rezensionen der ersten vier Übersetzungsbände in der von ihm selbst begründeten Zeitschrift für Wissenschaft und Kunst. ${ }^{94}$ Sie dokumentieren durchgängig Friedrich Asts kritische, wenn nicht gar feindselige Haltung gegenüber Schleiermacher. ${ }^{95}$ Friedrich Ast bleibt der einzige, der sich auch in der Folgezeit fortlaufend mit Schleiermachers Arbeit am Platon explizit auseinandersetzt. Für den dritten Band erscheint besonders wichtig sein Werk „Platon's Leben und Schriften" von 1816, das auch von Schleiermacher für die zweite Auflage des dritten Bandes gelegentlich herangezogen wird.

Außerdem stellen August Boeckhs und Friedrich Asts Rezensionen der Platonausgabe Ludwig Heindorfs eine implizite, häufig sogar explizite Auseinandersetzung mit Schleiermacherschen Auffassungen dar.

Es sind damit im Wesentlichen folgende Publikationen, die für die unmittelbare Rezeption der Schleiermacherschen Platonübersetzung (Band II,1) einschlägig sind:

1806: Anonyme Rezension zu Band I,1-2 und II,1, in: Neue Leipziger Literaturzeitung, 90. Stück, 1806, Sp. 1425-1439

1808: Rezension von Friedrich Ast zu Band II,1-2, in: Zeitschrift für Wissenschaft und Kunst, hrsg. von Friedrich Ast, Erster Band, Viertes Heft, Landshut 1808, S. 60-83

1808: Rezension von August Boeckh zu den ersten drei PlatonBänden Heindorfs samt Studienausgabe, hier einschlägig also: Platonis dialogi duo, Gorgias et Theaetetus, emend. Lud. Frid. Heindorf. Accedit auctarium animadversionum Ph. Buttmanni, Berlin 1805; Platonis libri quatuor. Gorgias, Apologia Socratis, Charmides, Hippias Maior, scholarum in usum edidit L. F. Heindorf, Berlin 1805; Platonis dialogi tres. Cratylus, Parmenides, Euthydemus, emendavit et annotatione instruxit Lud. Frid. Heindorf, Berlin 1806, in: Jenaische Allgemeine Literatur-Zeitung, Julius, August, September 1808, Nr. 176, Sp. 177-184. Nr. 177, Sp. 185-192. Nr. 178, Sp. 193-200

93 Zur Person Friedrich Asts und seinem Verhältnis zu Schleiermacher s. Lutz Käppel: Die frühe Rezeption der Platon-Übersetzung Friedrich Schleiermachers am Beispiel der Arbeiten Friedrich Asts, in: Geist und Buchstabe. Interpretationsprozesse innerhalb des Christentums. Festschrift für Günter Meckenstock zum 65. Geburtstag, herausgegeben von Michael Pietsch und Dirk Schmid (Theologische Bibliothek Töpelmann Bd. 164), Berlin / New York 2013, S. 45-62.

95 Vgl. KGA IV/3, S. XXXVII, sowie oben Anm. 93. 
1809: Rezension von Friedrich Ast zu Platonis dialogi duo, Gorgias et Theaetetus, emend. Lud. Fr. Heindorf. Accedit auctarium animadversionum Ph. Buttmanni, Berlin 1805, in: Zeitschrift für Wissenschaft und Kunst, hrsg. von Friedrich Ast, Zweiter Band, Erstes Heft, Landsbut 1809, S. 56-71 (eine Auseinandersetzung mit den HeindorfSchleiermacherschen Lesarten)

1813: Rezension von Ferdinand Gotthelf Hand zu Band I,1-2. II,1-3, in: Jenaische Allgemeine Literaturzeitung, Januar 1813, Sp. 137-158

1816: Friedrich Ast: Platon's Leben und Schriften. Ein Versuch, im Leben wie in den Schriften des Platon das Wabre und Aechte vom Erdichteten und Untergeschobenen zu scheiden, und die Zeitfolge der ächten Gespräche zu bestimmen. Als Einleitung in das Studium des Platon, Leipzig 1816

\section{Die Entstehung der 2. Auflage (1818)}

Von der Entstehung der zweiten Auflage des dritten Bandes sind - wie von der der übrigen Bände - nur noch wenige Spuren greifbar. Schleiermacher ist 1807 aus Halle nach Berlin zurückgekehrt, wo er 1809 Prediger an der Dreifaltigkeitskirche, 1810 Professor der Theologie an der neu gegründeten Friedrich-Wilhelms-Universität und erster Dekan der Theologischen Fakultät, schließlich 1811 Mitglied der Preußischen Akademie der Wissenschaften geworden war. Die erste Auflage des Schleiermacherschen Platon erfolgte maßgeblich auf der Grundlage der Arbeiten Ludwig Friedrich Heindorfs. Dieser war nach seiner Berufung auf die Berliner Professur 1809/10 einem Ruf nach Breslau (1811) und bald darauf einem Ruf nach Halle (1815) gefolgt. ${ }^{96}$ Doch sein Gesundheitszustand verschlechterte sich so sehr, dass er bereits im Juni 1816 verstarb. Damit stand er für die zweite Auflage nicht mehr als Kooperationspartner zur Verfügung.

Die zweite Auflage ist nun außerdem von der bereits in KGA IV/3 beschriebenen neuen Forschungssituation bestimmt, die durch die Arbeiten Immanuel Bekkers (1785-1871) entstanden war. ${ }^{97}$ Ab 1816 erschien in rascher Folge seine epochemachende und bis heute grundlegende Edition der platonischen Werke. ${ }^{98}$ Diese Ausgabe enthielt nur

\footnotetext{
96 Vgl. KGA IV/3, S. XL.

97 Vgl. KGA IV/3, S. XL-XLII.

98 Platonis Dialogi graece et latine ex recensione Immanuelis Bekkeri, 8 Bde., Berlin 1816-1818.
} 
den von Bekker auf der Grundlage der von ihm selbst neu kollationierten Handschriften konstituierten Text und die lateinische Übersetzung des Ficino. Die wertvollen Handschriftenkollationen, die er im Auftrag der Akademie zwischen 1810 und 1812 angefertigt hatte, bzw. einen Apparat, der über die Lesungen Auskunft gibt, enthielt die Ausgabe nicht. Sie wurden erst 1823 separat publiziert. ${ }^{99}$ Schleiermacher liegen diese Kollationen allerdings bereits bei der Vorbereitung der 2. Auflage 1815 handschriftlich vor. Häufig verweist er in den Anmerkungen der 2. Auflage nicht nur auf die Edition, sondern auch auf die Lesungen Bekkers. ${ }^{100}$ Die enge Verbindung Bekkers mit Schleiermacher und die hohe Wertschätzung Schleiermachers als Platonübersetzers durch Bekker wird zudem dadurch deutlich, dass Bekker Schleiermacher seine Edition widmet: „Friderico Schleiermachero Platonis restitutori d. Editor" ( $p$. V), aber auch dadurch, dass Bekker in der Anordnung der Dialoge in seinen Bänden der von Schleiermacher mit philosophischem Bedacht gewählten (und keineswegs überlieferungstechnisch begründeten) Anordnung folgt.

Für den vorliegenden dritten Band ergibt sich zusätzlich eine besondere Situation: Da Schleiermacher die Heindorfsche Ausgabe des Gorgias, des Theaitetos und des Euthydemos zwar schon lange in vorläufigen Fassungen kannte, aber bei der letzten Überarbeitung seines eigenen Bandes nicht mehr vollständig in ibrer endgültigen Fassung berücksichtigen konnte, gibt es in der ersten Auflage noch Spuren, die zeigen, dass die bis dahin gängige Bipontina ursprünglich zu Grunde lag. Die Folge war, dass Schleiermacher erst zur zweiten Auflage (zusätzlich zu seiner Anpassung der Übersetzung an den neuen Bekkerschen Text) seine Übersetzung an manchen Stellen gleichsam nachträglich auch auf die Heindorfsche Edition umstellte. ${ }^{101}$

99 Immanuel Bekker: In Platonem a se editum commentaria critica. Accedunt scholia, 2 Bde., Berlin 1823.

100 Siehe Schleiermacher in KGA IV/3, S. 91, Spalte 4, Z. 14-19 (W² Anm. 1); vgl. auch die Briefe an und von I. Bekker, in: Briefwechsel Friedrich Schleiermachers mit August Boeckh und Immanuel Bekker. 1806-1820, hrsg. von Heinrich Meisner, Berlin 1916, S. 47. 50. 58. 65. 67. 72. 74. 76. 77. 80. 88. 90. 93, wo Bekker ab Mai 1817 von seiner Italienreise über seine Platon-Kollationen allgemein, insbesondere aber auch über die der italienischen Codices spricht.

101 Siehe z. B. im Theaitetos S. 505. 517; im Gorgias sind die Corrigenda der Heindorfschen Ausgabe erst für die zweite Auflage berücksichtigt. In einigen Anmerkungen in $W^{1}$ zeigt sich noch, dass Schleiermacher auf der Grundlage der Bipontina die Anmerkungen erarbeitet und nicht mehr vollständig mit Heindorfs Edition abgeglichen hat: z. B. Euthydemos $\mathrm{W}^{1}$ Anm. 54, wo die entsprechende Anmerkung in $\mathrm{W}^{2}$ (Anm. 55) gleichsam überflüssig ist, da die vorgeschlagene Korrektur schon bei Heindorf in der Edition aufgenommen ist. Auch in den Anmerkungen, die in 
Von den Rezensionen findet nur die von Friedrich Ast zur ersten Auflage sowie sein Buch "Platon's Leben und Schriften" bei der Überarbeitung des dritten Bandes für die 2. Auflage Beachtung. ${ }^{102}$

Wann Schleiermacher die Neubearbeitung in Angriff nimmt, ist nicht mehr eindeutig festzustellen. Erste Arbeiten scheinen im September 1815 zu beginnen. ${ }^{103}$ Im Oktober 1815 stehen die Arbeiten am ersten Band jedenfalls kurz vor dem Ende. ${ }^{104}$ Im Juni 1817 beschäftigt sich Schleiermacher ebenfalls mit der Überarbeitung, offenbar zum dritten Band II,1. ${ }^{105}$ Im Jahr 1818 erscheint dann der Band II,1 in zweiter Auflage.

Wiederum bleiben die von Schleiermacher erhofften Rezensionen aus. Allein der alte Widersacher Schleiermachers, der inzwischen arrivierte Platoniker Friedrich Ast, publiziert abermals eine vernichtende Rezension, diesmal zu den beiden Bänden des ersten Teiles und zum ersten des zweiten Teiles zusammen:

Ast, Friedrich: [Rezension zu] Platon's Werke von F. Schleiermacher. Ersten Theiles, erster und zweyter Band, und zweyten Theiles erster Band. Zweyte verbesserte Auflage. Berlin 1817, 1818. [...], in: Jahrbücher der Literatur, Bd. 7, herausgegeben von Matthäus $v$. Collin, Wien 1819, S. 55-80.

$W^{2}$ gegenüber $W^{1}$ hinzugefügt wurden, hat in einigen Fällen eine erneute, explizite Auseinandersetzung mit Heindorfs Edition und besonders auch seinen Kommentarnoten stattgefunden: z. B. Theaitetos $W^{2}$ Anm. 23. 36. 43; Euthydemos $W^{2}$ Anm. 12. 19. 39. 43. 48.

102 Siehe oben zu 4. Erste Reaktionen und Rezensionen.

103 Siehe den Brief an I. Bekker, 17.9.1815, in: Briefwechsel Schleiermachers mit Boeckh und Bekker, hrsg. von H. Meisner (wie Anm. 100), S. 45: „Am Platon bin ich, aber viel wird es bis jezt auch noch nicht, und manches Bedenken bleibt zurück. Boeckhs Kritik hat mich hie und da in Versuchung gesezt, die Anmerkungen über meinen Plan hinaus zu erweitern, aber ich habe doch ziemlich widerstanden."

104 Siehe den Brief an I. Bekker, 20.10.1815, in: Briefwechsel Schleiermachers mit Boeckh und Bekker, hrsg. von H. Meisner (wie Anm. 100), S. 47: „Draußen (sc. außerhalb des neu bezogenen Hauses) habe ich nichts gethan, als die Revision meines ersten Plato Bandes für den neuen Abdruk fast vollendet. So eine zweite Ausgabe ist immer ein wunderliches Flikwerk. In der Uebersezung ist vieles - ich hoffe verbessert und nicht verballhornt, und Ihre Collationen haben mir manchen Dienst geleistet; indes es giebt leider doch auch noch so schlimme Kreuze, wo sie nichts leisten. In den Anmerkungen aber läuft erschrecklich bunt altes und neues durcheinander, und ich habe das nicht vermeiden können."

105 Der Brief an I. Bekker, 22.6.1817, in: Briefwechsel Schleiermachers mit Boeckh und Bekker, hrsg. von H. Meisner (wie Anm. 100), S. 52, bezieht sich vielleicht noch auf den zweiten, eher aber auf den dritten Band. 


\section{Die Handschriften zu den vier Dialogen des Bandes II,1 und ihre Entstehung}

\section{Gorgias}

\subsection{Handschriften aus der Phase der Vorbereitung der Publikation bei Friedrich Frommann}

Handschriftliches Material zum Gorgias ist nicht erhalten. Zur Vorbereitung der Publikation bei Friedrich Frommann war nur die Zuständigkeit für den Gorgias geklärt worden. Mit der Übersetzungsarbeit hat Schleiermacher in dieser Phase nicht begonnen; er hat offenbar Heindorfs Arbeit an der Edition des Gorgias abgewartet bzw. teilweise begleitet.

Die Planung für die Übersetzung des Gorgias in dieser Phase lässt sich aus dem Briefwechsel Schleiermachers rekonstruieren: ${ }^{106}$

- April 12. F. Schlegel plant den zweiten Band der Platon-Übersetzung u. a. mit dem Gorgias und fragt, ob Schleiermacher den Gorgias übernehmen will107

- April 18. Schleiermacher verpflichtet sich gegenüber F. Frommann voraussichtlich bis Weihnachten den Kratylos und ggf. auch den Gorgias zu übersetzen ${ }^{108}$

- Mai 21. F. Frommann vertraut darauf, dass Schleiermacher den Gorgias übernimmt, falls F. Schlegel ibn nicht liefert ${ }^{109}$

106 Vgl. auch KGA V/5, S. XXX; KGA V/6, S. XIX-XXVII.

107 KGA V/5, Nr. 1206 von F. Schlegel, 12.4.1802: „In [den] 2ten Band kämen alsoTheätetos, Gorgias, Sophistes, Politikus [sic] und Kratylos. - Wolltest Du auch noch den Gorgias nehmen, oder soll ich ibn behalten?" (Z. 40-42 = KFSA 25, Nr. 253, S. 354).

108 KGA V/5, Nr. ${ }^{* 1215}$ an F. Frommann, 18.4.1802.

$109 \mathrm{KGA} \mathrm{V/5,} \mathrm{Nr.} 1234$ von F. Frommann, 21.5.1802: „Schlegel verspricht den Gorgias, den aber im Nothfall auch $S i$ e liefern werden, wenn, - wie er nicht zugeben will - er uns wieder in Stiche ließ. So hoffe ich in den ersten Monaten des künftigen Jahres den 2ten Band ausgeben zu koennen [...]" (Z. 47-50). 
- Mai 22. F. Schlegel will den Gorgias nun doch selbst übernebmen ${ }^{110}$

- August 26. Heindorf schiebt seine Bearbeitung des Gorgias auf, um jeweils an denselben Dialogen zu arbeiten wie Schleiermacher ${ }^{111}$

- Oktober ca. 18.-26. Heindorf schickt Material zu Stellen im Gorgias (485e und 506b) an Schleiermacher ${ }^{112}$

- Oktober 22. F. Frommann erwartet von F. Schlegel den Gorgias bis zum geplanten Beginn des Druckes des zweiten Bandes im Januar ${ }^{113}$

1803

- März 2. Heindorf hat Material u. a. zum Gorgias gesammelt und den griechischen Text an zablreichen Stellen emendiert ${ }^{114}$

110 KGA V/5, Nr. 1236 von F. Schlegel und D. Veit, 22.5.1802: „Da Frommann sehr $z u$ wünschen scheint, daß ein Dialog auch von mir sei, so wollen wir für jetzt wenigstens den Gorgias auf meinen Theil rechnen. Sobald aber nur der geringste Zweifel eintritt, ob ich ihn zur bestimmten Zeit liefern kann, so melde ichs gleich, und nehme für diesen Fall Dein Anerbieten an." (Z. 14-19 = KFSA 25, Nr. 263, S. 364).

111 KGA V/6, Nr. 1320 von L. F. Heindorf, 26.8.1802: „In meiner Lectüre werde ich nun ganz den Gang nehmen, den Du nimmst, damit wir immer ganz gleiches Interesse haben, also den Gorgias und andere schon gewählte noch aufschieben." (Z. 115-118).

112 KGA V/6, Nr. 1364 von L. F. Heindorf, 18.10. (oder früher) bis 26.10.1802: „Über die Stelle vom Amphion und Zethus im Gorgias ist nachzusehn Valckenaer Diatribe in Euripidis Reliquias p. 70 seqq. und Piersonus Praefatio ad Moeridem p. 43. seq. wo er die Verse herzustellen sucht. Beide Bücher habe ich jetzt nicht bei der Hand [...]" (Z. 136-140).

113 KGA V/6, Nr. 1366 von F. Frommann, 22.10.1802: „An Friedrich will ich sogleich schreiben, daß ich auf seinen Gorgias bis dahin gewis rechnete [...]" (Z. 37-39).

114 KGA V/6, Nr. 1444 von L. F. Heindorf, 2.3.1803: „Über den Theätet habe ich gar viel zur Erklärung zusammengebracht, so daß ich wohl jetzt einen Commentar darüber schreiben könnte, ebenso über den Gorgias, wo der Findeisen in seiner sonst höchst miserabeln Arbeit doch durch Codices viel Hülfe geschaft hat, und wo ich wohl 50 Stellen ex ingenio emendirt habe, daß nun fast gar keine Dunkelheit mehr bleibt." (Z. 87-92). 


\subsection{Handschriften zur Vorbereitung des Druckes bei Georg Andreas Reimer}

Handschriftliches Material aus dieser Druckphase ist nicht erhalten, doch lassen sich folgende Handschriften erschließen:

1. Einleitung (verloren)

2. Übersetzung (verloren)

3. Anmerkungen (verloren)

Die verlorenen Handschriften sind vermutlich nach Einarbeitung der Korrekturen als Druckvorlagen an den Verlag geschickt worden.

Die Entstehung der oben genannten Handschriften lässt sich aus dem Briefwechsel Schleiermachers rekonstruieren:

\section{3}

- September 3. Heindorf plädiert zum schnelleren Verkauf der Übersetzung dafür, Phaidon, Gorgias $u$. a. vor den schwierigen Dialogen wie Theaitetos herauszubringen ${ }^{115}$

- Dezember 30. Heindorf hat die Noten zum Gorgias ausgearbeitet und muss sich für die weitere Bearbeitung die Ausgabe von Routh besorgen ${ }^{116}$

\section{4}

- Februar 11. Heindorf schickt die restlichen Noten zum Gorgias und seinen nahezu vollständig emendierten griechischen Text und

115 KGA V/7, Nr. 1544 von L. F. Heindorf, 3.9.1803: „Dialogen, wie Phädon, Gorgias u.s.w. müßten dächte ich, vor den abstrusen vorhergehen. Meinst Du wobl, daß es in unserm lieben Vaterlande funfzig Menschen giebt, die den übersetzten Parmenides oder Theätet oder Sophista lesen werden? Mit dem Phädon Brüderchen, sind wir durchgekommen; im Gorgias bin ich auch ganz aufs Reine; dazu noch Phädrus und Protagoras, das lockte gewiß Käufer herbei, und gäbe wenigstens zu einem zweiten Bande Aussicht." (Z. 72-79).

116 KGA V/7, Nr. 1626 von L. F. Heindorf, 30.12.1803: „[...] unmittelbar vor der Krankheit hatte ich vierzehn Tage, wo ich [...] die Noten zum Gorgias ausarbeiten konnte [...]“ (Z. 19-21) „Am Plato werde ich in den ersten Wochen wohl nichts schriftlich arbeiten können, sosehr mich auch der Gorgias drängt und treibt. Zudem läßt sich doch ohne die Ausgabe von Routh nicht viel anfangen, die ich aus Gedikens Büchern quovis pretio erstehen muß." (Z. 33-36). 
bittet um Schleiermachers Korrekturen; ${ }^{117}$ ferner bittet er um Mitteilung von Aristoteles-Zitaten $u$. a. aus dem Gorgias ${ }^{118}$

- März 13. Heindorf hat noch Nachträge zum Gorgias ${ }^{119}$

- Oktober 30. Schleiermacher denkt schon an den dritten Band des Platon ${ }^{120}$

- November 4. Schleiermacher schreibt an Reimer, dass er schon ein wenig am dritten Band arbeitet ${ }^{121}$

- Dezember vor Mitte bis 15. Schleiermacher erwartet, bald nach Neujabr mit der Hauptarbeit beginnen zu können ${ }^{122}$

117 KGA V/7, Nr. 1656 L. F. Heindorf, 11.2.1804: „Hier [...] die Fortsetzung und Beendigung meiner Noten zum Gorgias.“ (Z. 1 f.). „Meine Sachen zum Gorgias würde ich Dir auf ganz unbestimmte Zeit überlassen, wenn ich mich jetzt mehr vom Plato trennen könnte. Die Arbeit ist, wie Du selbst finden wirst, noch roh, und bedarf auf jeder Seite noch erläuternder und beweisender Stellen. [...] Auch denke ich, Du wirst mit der Lectüre des Gorgias nun gar leicht und bald fertig werden, da ich den Text, großentheils durch Manuscripte, so lesbar gemacht habe, daß nur an wenigen Stellen Zweifel übrig bleiben; an 150 Ändrungen kommen in den Text. Stelle Dir nur vor, daß ich von Dir durchaus noch wenigstens zehn Emendationen erwarte, und daneben gar viele Einwendungen und Zurechtweisungen am Rande der Hefte; kurz, mit wenigen Worten, je derber, desto besser. Zwischen hier und Ostern ist für einen Menschen, wie Du bist, noch viel Zeit. Wenn ich sie dann zurück bekomme, bin ich zufrieden. Auf jedenfall wirst Du die Noten nicht so schändlich lange behalten, als ich die Deinigen zum Sophista und Alcibiades, aber wie ists mir auch seither gegangen! Den Routh habe ich erst bei dieser Fortsetzung benutzen können; so ganz übel ist er nicht [...] Den Findeisen werde ich wohl in den Noten gar nicht erwähnen dürfen, so schlecht habe ich ihn gefunden [...] Ich habe übrigens alle Varianten in meinen notulis zusammengetragen, auch um Deinetwillen; es versteht sich, daß in die ausgearbeiteten Noten nur die bedeutendern, nicht alle sordes, kommen. " (Z. 59-88).

118 KGA V/7, Nr. 1656 (wie oben): „Wenn Du im Aristoteles Citationen aus dem Gorgias, Euthydem, Cratylus und Theätet gefunden hast, so theile sie mir doch gelegentlich mit. Ebenso schreib mir doch an den Rand des Heftes, wieviel von den Worten des Polus im Gorgias Aristoteles citirt." (Z. 93-96).

119 KGA V/7, Nr. 1684 L. F. Heindorf, 13.3.1804: „Zum Gorgias habe ich seither auch noch manche Erläuterungen und Bestätigung gefunden." (Z. 22-24).

${ }^{120}$ KGA V/8, Nr. 1841 an Henriette und Johann Ehrenfried Theodor von Willich, 30.10.1804: „Hie und da kann ich nun doch ein wenig an den dritten Band des Platon denken." (Z. 57 f.).

${ }^{121} \mathrm{KGA} \mathrm{V/8,} \mathrm{Nr.1844}$ an G. A. Reimer, 4.11.1804: „Ich arbeite bisweilen schon ein wenig für den 3ten Band des Plato, aber freilich noch will es nicht viel sagen." (Z. 32 f.).

122 KGA V/8, Nr. 1878 an G. A. Reimer, vor Mitte Dezember bis 15.12.1804: „Die Kiste und in ihr der Velin Plato sind glüklich angekommen; und lezterer hat mir nun wieder große Sehnsucht nach dem dritten Theil gegeben. Wenn nur Süvern seine Ausstellungen zum Besten gäbe und man sonst etwas von gründlichen 
- Januar 14. Schleiermacher teilt Reimer mit, dass Heindorfs Edition u. a. des Gorgias im Druck ist und er aufgrund dieser seine Übersetzung erarbeiten kann; will den Band im Sommer fertig machen $^{123}$

- Februar Schleiermacher wird vor März von der Übersetzung nichts fertigstellen; der Druck von Heindorfs Edition ist unterbrochen; Spalding steht für die Korrektur nicht zur Verfügung 124

- März 21. Schleiermacher kündigt Reimer u. a. den Gorgias samt Einleitung an ${ }^{125}$

- März 23. Heindorf schickt die Druckbogen seiner Edition des Gorgias und ist gespannt auf Schleiermachers Urteil; Buttmann hat grobe Versehen korrigiert; Heindorf teilt seine Meinung zu einigen zwischen ihm und Schleiermacher umstrittenen Stellen mit ${ }^{126}$

Kritiken zu Gesicht bekäme ehe die rechte Arbeit wieder angeht, was denke ich bald nach Neujabr geschehen soll." (Z. 1-5).

123 KGA V/8, Nr. 1898 an G. A. Reimer, 14.1.1805: „Zufällig habe ich Dir wol nicht gesagt, daß an der zweiten Heindorfischen Sammlung Platonischer Dialogen die sich Nauk doch nicht hat nehmen lassen schon gedrukt wird. Dies erleichtert mir die Arbeit zum nächsten Band; da 3 große Dialogen dieselben sind, gar sehr, und ich habe nun noch viel so große Zuversicht ihn im Sommer fertig zu machen. Kann ich irgend vor Ostern noch etwas liefern: so soll es geschehn, doch zweifle ich bieran [...]“ (Z. 44-49).

124 KGA V/8, Nr. 1927 an G. A. Reimer, Februar 1805: „Manuscript zum Plato werde ich Dir gewiß nicht eher als im künftigen Monat, und zwar auch nicht im Anfang senden können. Ich habe aber ein Project gemacht was hernach der Förderung des Ganzen auch sehr heilsam sein wird. Doch muß ich erst noch Erkundigung einziehn ob ich wol auf das Gelingen rechnen kann. Ich will nemlich meine Reise nach Schlesien in den Julius oder August verlegen [...] Dann kann ich vorher den Plato in einem Strich beseitigen - Heindorfs Druk ist wie ich fürchte Krankheits wegen unterbrochen was mir auch sehr fatal ist da die beiden ersten Dialogen unseres Bandes bei ihm vorkommen. “ (Z. 16-25). „Daß Spalding nach Italien reist ist doch ein garstiger Verlust für den Plato; ich muß mir nun zwei Augen mehr anschaffen." (Z. 53 f.)

125 KGA V/8, Nr. 1938 an G. A. Reimer, 21.3.1805: „Vom Plato bekommst Du den Gorgias nebst Einleitung und die Einleitung zum Theaetet 9-10 Bogen zusammen, wahrscheinlich auch ein Stück des Gespräches selbst vor meiner Abreise, und so werden sie wol auf 4 bis 5 Wochen genug haben. Wie weit alles übrige ist hast Du ja gesehen und kannst daraus die beste Zuversicht schöpfen." (Z. 19-23).

126 KGA V/8, Nr. 1939 von L. F. Heindorf, 23.3.1805: „Wäre der Gorgias eher fertig geworden, so hätte ich ihn Dir gewiß schon geschickt. Der Buchdrucker versprach ihn in sechs Wochen zu liefern, und nun ist über ein Vierteljahr daraus geworden, so daß mit genauer Noth noch der Theätet zur Messe fertig werden kann. [...] Wie Du mit dem Gorgias zufrieden sein wirst, weiß ich nicht; ich finde schon jetzt, daß 
- März/April Schleiermacher teilt Reimer mit, dass u. a. der erste Entwurf des Gorgias fertig ist und dass bald nach der Messe der Druck beginnen kann ${ }^{127}$

- Ende April/Anfang Mai Schleiermacher schickt Heindorf (wohl) Manuskripte der Platon-Übersetzung und einen Auftrag an Buttmann ${ }^{128}$

- vor Juli 29. Reimer bittet um Fertigstellung des Manuskriptes für den Band 2,1 der Platon-Übersetzung in sechs Wochen ${ }^{129}$

- Juli 29. Schleiermacher findet den von Reimer angesetzten Termin problematisch; 130 findet die Korrektur der Aushängebogen des Gorgias samt Einleitung auf den ersten Blick gut ${ }^{131}$

- Anfang August Reimer schickt weitere Aushängebogen vom Gorgias $^{132}$

ich vieles noch genauer hätte erklären sollen. Grobe Versehen wirst Du nicht finden. Davor hat mich Buttmanns liebevolle Theilname bewahrt, nach dessen Erinnrungen ich noch in den Correcturbögen viel geändert habe, so daß mir mancher Bogen [...] über 2 Thlr kostet. Da gewiß wenige oder keiner meine Arbeit so prüfen wird, als $D u$ bei der Übersetzung, so wird mir Dein Urtheil darüber instar omnium sein. Der Beispiele sind gewiß hie und da zu viele, zuweilen auch wohl da welche, wo man sie nicht erwartet; auch hätte ich so manche Lesart einiger Codices die ich in den Noten gebilligt, in den Text setzen sollen, sowie auch manche Emendazionen [...]" (Z. 28-50). - Zu Gorgias 447b-c.448e.449e.453c (s. u. jeweils z. St.): KGA V/8, Nr. 1939, Z. 107-129.

127 KGA V/8, Nr. 1949 an G. A. Reimer, März/April 1805: „Am Plato arbeite ich izt täglich. Allein ich kann bei diesem Bande kaum anders als zuvor die erste Bearbeitung des Ganzen fertigen ehe ich an die lezte eines einzelnen Dialogs gehe. Auch kann Dir izt wol nichts am Anfang des Druks gelegen sein. Die erste Arbeit des Gorgias und Theaetets ist fertig, auch fast der halbe Euthydem, nun ist nur noch die Hälfte von diesem und der Menon übrig, und diese beiden leztern sind bei weitem die kleinsten. Bald nach der Messe denke ich soll der Druk angehn können. " (Z. 39-46).

128 KGA V/8, Nr. "1960 an L. F. Heindorf, Ende April/Anfang Mai 1805.

129 KGA V/8, Nr. *2003 von G. A. Reimer, vor dem 29.7.1805.

${ }^{130}$ KGA V/8, Nr. 2004 an G. A. Reimer, 29.7.1805: „Sechs Wochen [...] sind doch eigentlich ein sehr kurzer Termin. Es muß mir außerordentlich glüklich gehn, das heißt der Himmel muß mir recht viele gute Stunden verleihen und mich vor allen Störungen [...] bewahren wenn ich sobald soll fertig werden. Fast würde das mechanische Schreiben soviel Zeit erfordern. [...]" (Z. 2-6).

131 KGA V/8, Nr. 2004 (wie oben): „Auch die Aushängebogen habe ich nur erst flüchtig angesehn und die Correctur sehr gut gefunden. Nur in der Einleitung giebt es glaube ich einen garstigen Fehler, wo einmal Polos statt Gorgias steht das kann aber auch leicht ein Schreibfehler von mir sein" (Z. 22-26).

132 KGA V/8, Nr. 2009 von G. A. Reimer, Anfang August 1805: „Ich schicke Dir die Aushängebogen 7.8. - seit länger als 14 Tagen feiern die Setzer schon. [...] Vom 
- August Schleiermacher bestätigt den Eingang der Aushängebogen, die allerdings nicht vollständig sind ${ }^{133}$

- August Heindorf bietet seine Hilfe bei der Korrektur der Übersetzung an ${ }^{134}$

- September 6. zum dritten Band feblt noch die letzte Hälfte des Euthydemos und die Redaktion der Anmerkungen ${ }^{135}$

- September 7. Reimer schickt u. a. den feblenden Aushängebogen des Gorgias; der Band wird etwa 30 Bogen stark werden; bittet Schleiermacher, möglichst bald die Anmerkungen zu senden; kann Korrekturen nicht ganz übernehmen, da er verreist ${ }^{136}$

Plato schicke mir wo möglich etwas, wenn auch nur den Anfang des Theätet, damit wir etwas weiter kommen [...]." (Z. 9-16).

133 KGA V/8, Nr. 2011 an G. A. Reimer, August 1805: „Deine Sendung ist richtig eingelaufen: aber lieber Freund die erste enthielt vom Gorgias die Bogen 1-5 die zweite 7 und 8 und 6 ist mir defect; ich bitte mir ihn ja aus damit mir das Exemplar nicht verloren geht." (Z. 9-12).

134 KGA V/8, Nr. 2010 von L. F. Heindorf, August 1805: „A propos! Wird denn Deine Übersetzung hier gedruckt? Und ich kriege gar nichts davon zu sehen? Nichts $z u$ revidiren oder corrigiren? Du hast mich wohl sonst damit verschonen wollen; aber von nun an werde ich es im eignen Arbeiten sachte angehn lassen, da die Noten zu den 3 Dialogen bis auf die letzte Überarbeitung fertig liegen, und da könnte ich wobl eine Correctur übernehmen, wobei ich vielleicht ein und das andre für Deine Noten bemerkte. Willst Du das, so gieb gleich Ordre dazu an Reimann [gemeint ist Reimer]. " (Z. 73-80).

135 KGA V/8, Nr. 2026 an J. C. Gaß, 6.9.1805 bis 13.9.1805: „[...] wenn der dritte Band vollendet ist; daran fehlt nur noch die lezte Hälfte des Euthydemos und die Redaction der Anmerkungen. Ich denke Sie sollen auch Freude haben an dem Stükk Arbeit, zumal am Gorgias und Theätetos; und wenn mich nicht Voreingenommenheit gänzlich verblendet: so hoffe ich ist in den Einleitungen dieses Bandes ein tüchtiger Grund gelegt um meiner Anordnung den Beistand der verständigen Leser zu sichern." (Z. 16-22). Vgl. dazu KGA V/9, Nr. 2245 von J. C. Gaß, 23.8.1806, bes. Z. 100-112.

136 KGA V/8, Nr. 2027 von G. A. Reimer, 7.9.1805: „Hier liebster Freund, die Aushängebogen 6 und 9-13; doch habe ich eben 16 zur Correctur erhalten. Bis zum Schluß des Theätet wird dieser Band 20 Bogen betragen [...] so wird dieser Band wohl einige dreißig Bogen stark werden. Einen Transport Aushängebogen sende $i c h$ dann noch in 8 Tagen und werde Auftrag geben, daß man Dir die übrigen von Zeit zu Zeit übersende. Sei Du dann aber ja so gut die Anmerkungen, so viel möglich zu fördern; schicke allenfalls den Rest zur reitenden Post. Ohnehin wird der Band spät genug fertig [...] Dann thut es mir auch leid, daß ich die Correcturen nicht ganz übernehmen, und die Versendung nicht besorgen kann, meiner Reise wegen." (Z. 2-14). 
- vor September 9. Schleiermacher bittet Friedrich Christian Jösting (1772-1840), Reimer an die Übersendung von Aushängebogen zur Platon-Übersetzung zu erinnern ${ }^{137}$

- September 9. Schleiermacher geht davon aus, dass bis zum Ende des Monats der Druck des dritten Bandes abgeschlossen sein kann; hofft, am übernächsten Tag Aushängebogen des Gorgias und Theaitetos zu erhalten; will die Anmerkungen in spätestens 16 Tagen schicken $^{138}$

- September 14. Schleiermacher will die Anmerkungen in etwa acht Tagen an Reimer schicken; es erscheint ibm sinnlos, Heindorf die Anmerkungen vorher mitzuteilen, da dessen Band noch nicht fertig gedruckt ist ${ }^{139}$

- September 18. Reimer schreibt, der Band werde mehr als 30 Bogen stark; Schleiermacher ist dem Setzer um acht Bogen voraus, die Anmerkungen eilen also nicht; Heindorf wird die Korrektur besorgen und kann dann leicht die Seitenverweise in den Anmerkungen hinzufügen $^{140}$

- wohl September 23. Schleiermacher hat die Anmerkungen abgeschlossen und will sie am folgenden Tag schicken ${ }^{141}$

137 KGA V/8, Nr. *2028 an Jösting, vor dem 9.9.1805.

138 KGA V/8, Nr. 2031 an G. A. Reimer, 9.9.1805: „Nun glaube ich bestimmt abzusehen, daß am Ende des Monats der Druk beendigt sein kann, und bin also hierüber ganz rubig. Um baldige Aushängebogen vom Gorgias und Theätetos habe ich Dich durch Jösting mahnen lassen; sie thun mir Noth für die Anmerkungen weil ich sonst nicht richtig citiren kann, und ich hoffe sicher deren Uebermorgen $z u$ erhalten. Dienstag über Acht Tage rechne ich Dir den Euthydemos zu schikken und spätestens Acht Tage drauf die Anmerkungen." (Z. 8-15).

139 KGA V/8, Nr. 2033 an G. A. Reimer, 14.9.1805: „Die Anmerkungen sollen wie ich zuversichtlich hoffe über acht Tage nachfolgen: denn sie sind schon fast ganz ausgearbeitet. [...] Ich glaubte bis Ende Theätetos 17 Bogen und die beiden andern Dialogen 6. Die Anmerkungen können höchstens 3 bis 4 Bogen geben. Werde ich bis Freitag fertig so schikke ich sie mit der Reitpost, es macht für den Drukk gewiß zwei volle Tage Unterschied. Die Anmerkungen Heindorf vorher mitzutheilen gebe ich auf; es ist auch nicht wesentlich da sein Buch immer noch nicht fertig gedrukt ist" (Z. 4-18).

140 KGA V/8, Nr. 2036 von G. A. Reimer, 18.9.1805: „Der Plato-Band wird gewiß 30 Bogen stark und darüber; doch thut das nun nichts. Die Anmerkungen brauchst Du nicht mit der reitenden Post zu schicken da Du dem Setzer jetzt schon um 8 Bogen voraus bist. [...] Vor dem 10-12ten wird schwerlich der Band fertig. Die Correctur besorgt Heindorf einmal und der kann leicht die Seitenzablen wegen der Anmerkungen beifügen. " (Z. 11-17).

141 KGA V/8, Nr. 2039 an G. A. Reimer, wohl 23.9.1805: „Die sämmtlichen Anmerkungen sind fertig und gehn Morgen mit der fahrenden Post ab" (Z. 30 f.). 
- Oktober 8. Schleiermacher bittet Reimer, ihm bald den Rest des Platon zu senden ${ }^{142}$

- Oktober 25. Schleiermacher hofft, den Rest des Platon zu bekommen; will über manches noch mit Heindorf sprechen ${ }^{143}$

- Oktober 30. Reimer hat Aushängebogen an Schleiermacher geschickt ${ }^{144}$

- November 9. Schleiermacher hat den dritten Band erhalten; er ist zur Messe nicht fertig geworden, aber stärker, als er gedacht hatte ${ }^{145}$

- Dezember 28. Heindorf schreibt, dass bei seiner Korrektur der Anmerkungen die Lemmata nicht immer mit den Worten der gedruckten Übersetzung übereinstimmten und er zudem Anmerkungen mit allgemeinem Bezug selbst zugeordnet hat ${ }^{146}$

142 KGA V/8, Nr. 2045 an G. A. Reimer, 8.10.1805: „Grüße Alles in Deinem Hause herzlich von mir und sende mir bald den Rest des Plato zu." (Z. 80 f.).

143 KGA V/8, Nr. 2061 an G. A. Reimer, 25.10.1805: „Ich hatte mit großer Gewißheit darauf gerechnet heute das übrige vom Plato zu bekommen denn wie rasch der Drukk ging nach Heindorfs Bericht muß Alles schon seit länger als 14 Tagen fertig sein. [...] Es ist mir Noth mich daran zu erfreuen, auch habe ich noch über Manches mit Heindorf zu conversiren." (Z. 2-8).

144 KGA V/8, Nr. 2064 von G. A. Reimer, 30.10.1805: „Kaum hatte ich gestern die Aushängebogen zur Post geschickt, wie ich Deinen Brief vom 25 empfing [...] Der Band ist stark geworden, wie Du sehen wirst, und der Abdruck der letzten Bogen zögert immer so etwas. " (Z. 2-8).

145 KGA V/8, Nr. 2071 an G. A. Reimer, 9.11.1805: „Der Plato ist glüklich angelangt. Leider aber sehe ich nun daß er gewiß nicht mehr zur Messe gekommen ist. Ich möchte gern meine Hände deshalb in Unschuld waschen da doch Ende September alles Manuscript da war, und wenn man fortdauernd, wie Heindorf damals sagte, täglich einen Bogen gedrukt hätte: so hätte er noch recht gut ankommen müssen. Stärker ist er allerdings geworden als ich dachte. " (Z. 2-7).

146 KGA V/8, Nr. 2104 von L. F. Heindorf, 28.12.1805: „Bist Du im Ganzen mit meiner Revision der Übersetzung zufrieden oder habe ich viel errata stehen lassen? Es ging zuletzt gar zu rasch. Aber Du Teufel hast mich recht gehetzt. Gegen das Ende der Noten hattest $D u$ da, wo ich die Seitenzahlen hinzufügen mußte, oft andre Worte gesetzt, als in der gedruckten Übersetzung standen, und einigemal wo die Note für etwas ganz allgemeines galt, habe ich alle mein bischen iudicium und Divination zusammennehmen müssen, um die richtige Seiten- und Zeilenzahl zu treffen." (Z. 179-186). 


\section{Theaitetos}

\subsection{Handschriften aus der Phase der Vorbereitung der Publikation bei Friedrich Frommann}

SN 166 Berlin BBAW, Nachlass F. Schleiermacher NS: $1664^{\circ}$ (Eigenhändige Notizen, o. D., $12 \mathrm{Bl}$.), Aufschrift auf $f .1^{r}$ : „Theaetetus", darunter „Lesung mit Heindorf", Notizen (f. $2^{r}-12^{r}$ mit einem Nachtrag zu f. $2^{r}$ auf f. $1^{v}$ ). Die Handschrift entstand anscheinend 1802 (vor dem 26. Mai). ${ }^{147}$ Die Handschrift ist sorgfältig geschrieben mit wenigen Streichungen, Korrekturen und Abbreviaturen. Abgekürzte Autorennamen und Werktitel in Literaturzitaten sowie abgekürzte Begriffe aus der grammatischen und editorischen Fachsprache sind belassen. Die Blattzählung ist sekundär.

Die Blätter sind durch Knick im Verhältnis zwei Drittel - ein Drittel bis drei Viertel - ein Viertel in Spalten geteilt, die (in der breiten Spalte) recto links, verso rechts mit den Notizen beschrieben sind.

Die einzelnen Notizen sind mit den Seitenzablen der Ed.Zweibrücken (Bipontina) auf die Stellen des griechischen Textes bezogen. Diese Seitenangaben sind in der Edition weggelassen und durch die Stephanusseitenzahlen mit dem Zusatz der Seitenzeile in dieser Edition ersetzt.

Die Notizen haben z. T. Eingang gefunden in die Anmerkungen (vgl. W' Anm.). In diesen Notizen, die Schleiermacher während der Lesung mit Heindorf gemacht hat, hat er $z$. T. genau vermerkt, wer der Urheber der einzelnen Gedanken ist. ${ }^{148}$

In der schmalen Spalte stehen Randnotizen verschiedener Art: (1) Lemmata zu einzelnen Noten; (2) nachträgliche Noten, und zwar (a) Text- und Sacherklärungen mit und obne Literaturangaben, (b) erneutes Aufgreifen früherer Positionen, ${ }^{149}$ (c) Notizen zur "zweiten Lesung " mit Heindorf in der ersten Hälfte der Handschrift (vor Ende Mai 1802)150.

147 Siehe oben Anm. 36.

$148 \mathrm{Vgl}$. besonders S. 580, Spalte 2 zu Theaitetos 163e. Vgl. dazu die allgemeine Anmerkung zum Parmenides: Platons Werke, von F. Schleiermacher, Ersten Theiles zweiter Band, Berlin ${ }^{1} 1805$, S. 401.

149 Vgl. z. B. SN 166, f. $2^{r}$ zu Theaitetos $144 a$ (s. u. S. 466, Spalte 2, Z. 17-20).

150 Die „zweite Lesung " ist explizit erwähnt SN 166, f. $3^{r}$ zu Theaitetos $149 d$ (s. $u$. S. 494, Spalte 2, Z. 24-26), f. $3^{r}$ zu 150a (s. u. S. 498, Spalte 2, Z. 12), f. $4^{v} z u$ $165 d$ (s. u. S. 590, Spalte 2, Z. 28), vgl. ferner f. $7^{r}$ zu $177 d$ (s. u. S. 658, Spalte 2, Z. 4). Im Übrigen sind auch Emendationen und Interpretationen Heindorfs ohne Verweis auf die zweite Lesung notiert. 
SN 300 Berlin BBAW, Nachlass F. Schleiermacher NS: $3004^{\circ}$ und $8^{\circ}$ (Briefe L. F. Heindorfs an Schleiermacher). Drei dieser Briefe enthalten Noten zu Platons Theaitetos, die in Spalte 2 nach KGA V/6, ggf. korrigiert aus der Handschrift, wiedergegeben sind. Dabei sind die Abkürzungen in der Regel nicht aufgelöst worden. Unterstreichungen bei Einzelbuchstaben in der Handschrift sind als Unterstreichung wiedergegeben. Die Briefe stammen vom 26. August, 18. Oktober oder früher bis 26. Oktober sowie November 1802 (KGA V/6, Nr. 1320 aus SN 300, f. $1^{r}-3^{r}$, Nr. 1364 aus SN 300, f. $4^{r}-6^{r}$, Nr. 1394 aus SN 300, f. $7^{r}-9^{v}$ ).

Zum Theaitetos sind also folgende Handschriften aus dieser Phase vorhanden bzw. zu erschließen:

1. Notizen zur Lesung mit Heindorf (SN 166)

2. (vermutlich) Entwurf der Übersetzung (entstanden wobl zwischen April und Juli 1802, verloren)

3. Noten Heindorfs in Briefen an Schleiermacher (SN 300)

Die Entstehung der oben beschriebenen Handschriften lässt sich aus dem Briefwechsel Schleiermachers rekonstruieren: ${ }^{151}$

1801

- November 16. Schlegel schlägt vor, dass Schleiermacher den Theaitetos übernimmt ${ }^{152}$

1802

- April 12. F. Schlegels Planung des zweiten Bandes der Platon-Übersetzung $u$. a. mit Theaitetos ${ }^{153}$

- April 18. Schleiermacher verpflichtet sich gegenüber F. Frommann bis Michaelis den Theaitetos, Sophistes und Politikos zu übersetzen ${ }^{154}$

151 Vgl. auch KGA V/5, S. XXVI-XXXII; KGA V/6, S. XX-XXVII.

152 KGA V/5, Nr. 1122 von F. Schlegel, 16.11.1801: „Du hast keine rechte Lust zum Phaedon; da schlage ich Dir denn gleich den Theätetus vor, der in jeder Rücksicht Dir zukömmt. [...] Möchtest Du nun doch mit dem Protagoras fertig sein und gleich rüstig an den Theätet gehn! Das würde mein Herz gar sehr erfreuen." (Z. 24-34 = KFSA 25, Nr. 203, S. 307).

153 Siehe oben Anm. 107.

154 KGA V/5, Nr. ${ }^{*} 1215$ an F. Frommann, 18.4.1802. 
- Mai 21. F. Frommann vertraut darauf, dass Schleiermacher bis Michaelis den Theaitetos, Sophistes und Politikos ausarbeitet ${ }^{155}$

- Mai 22. F. Schlegel ist erfreut, dass Schleiermacher den zweiten Band ganz oder größtenteils übernehmen will, besonders Theaitetos, Sophistes und Politikos ${ }^{156}$

- Mai 26. Heindorf schreibt an Friedrich August Wolf, dass er und Schleiermacher gemeinsam $u$. a. den Theaitetos gelesen und einen verlässlichen griechischen Text hergestellt haben; ${ }^{157}$ aus dieser Lesung mit Heindorf stammen Schleiermachers Notizen in SN 166

- Juni 26. Spalding fragt Schleiermacher nach der Bedeutung einer Stelle im Theaitetos $(176 a)^{158}$

- Juli 19. Schleiermacher arbeitet an der Übersetzung eines platonischen Dialogs, vermutlich (des Theaitetos oder) des Sophistes ${ }^{159}$

- August vor dem 20. Schleiermacher bittet Heindorf um Mitteilung seiner neuen Emendationen zum Theaitetos ${ }^{160}$

- August 26. Heindorf schickt Schleiermacher von diesem erbetene Emendationen zum Theaitetos (SN 300);161 er will seine Bearbeitung u. a. des Gorgias aufschieben, um jeweils an denselben Dialogen zu arbeiten wie Schleiermacher ${ }^{162}$

155 KGA V/5, Nr. 1234 von F. Frommann, 21.5.1802: „Sie, - auf deßen Wort ich, auch nach nur diesem einen Briefe, sicher baue - arbeiten bis zu Michaelis den Theaetet, Sophistes und Politicus aus [...]." (Z. 44-46).

156 KGA V/5, Nr. 1236 von F. Schlegel und D. Veit, 22.5.1802: „Daß Du den zweiten Theil ganz oder größtentheils übernehmen willst, ist mir höchst erfreulich; ich acceptire es bestimmt für den Theätet, Sophistes und Politicus." (Z. 12-14 = KFSA 25, Nr. 263, S. 364).

157 Siehe oben Anm. 147.

158 KGA V/6, Nr. 1263 von G. L. Spalding, 26.6. bis 11.7.1802: „Indem Plato sagt, das Böse könne nicht weggeschaft werden, weil dem Guten stets sein Gegentheil bleiben müße, meint er dadurch: ,ohne die Folie des Schmerzes könne kein empfindendes Wesen Gefühl des Wohlseins haben'? Oder was meint er, und meinen Sie mit ihm?" (Z. 33-36). Vgl. unten S. 652, Spalte 2, App. S zu 176a.

159 KGA V/6, Nr. 1283 an E. Grunow, 19.7.1802: „Jezt z. B. ist es die Uebersezung eines Platonischen Dialogs, wobei ich mir bestimmte Aufgaben mache." (Z. 12-14). Die Übersetzung des Sophistes ist laut KGA V/6, Nr. 1294 vom 10. August 1802, fast fertig (Z. 11 f.).

${ }^{160}$ KGA V/6, Nr. "1313 an L. F. Heindorf, vor dem 20.8.1802; vgl. KGA V/6, Nr. 1320, Z. $76 f$.

161 KGA V/6, Nr. 1320 von L. F. Heindorf, 26.8.1802: „Du verlangtest in Deinem ersten Briefe meine neuen Emendationen zum Theätet. Ich habe keine gemacht, außer [...]" Es folgen einzelne Noten. (Z. 76-87).

162 Siehe oben Anm. 111. 
- Oktober 18. oder früher bis 26. Heindorf bittet um Hilfe bei einer Theaitetos-Stelle und schickt weitere Noten zu einzelnen Stellen (SN 300)163

- wohl November Heindorf ist mit erster Arbeit über Theaitetos fertig geworden ${ }^{164}$ und schickt Noten zu einzelnen Stellen (SN 300)165

\section{3}

- März 2. Heindorf könnte über Theaitetos und Gorgias einen Kommentar schreiben, ${ }^{166}$ hat nach Weihnachten Emendationen zum Theaitetos und Schleiermachers Erklärung „der mathematischen Stelle" an H. K. A. Eichstädt geschickt ${ }^{167}$

\subsection{Handschriften zur Vorbereitung des Druckes bei Georg Andreas Reimer}

Handschriftliches Material aus dieser Druckphase ist nicht erhalten, doch lassen sich folgende Handschriften erschließen:

1. Einleitung (verloren)

2. Überarbeitung oder Neufassung der Übersetzung (verloren)

3. Anmerkungen (verloren)

163 KGA V/6, Nr. 1364 von L. F. Heindorf, 18.10. oder früher bis 26.10.1802: „Im

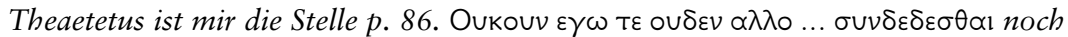
immer dunkel. Du thust mir einen großen Gefallen, wenn Du mir besonders die

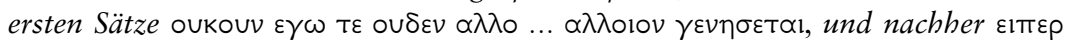
$\dot{\eta} \mu \omega \nu \mathfrak{\eta} \propto \nu \propto \gamma \kappa \eta \ldots \sigma \cup \nu \delta \varepsilon \delta \varepsilon \sigma \theta \propto \mathrm{l}$ einmal recht klar machst. Dafür will ich dir gleich einige Emendationen geben. [...]" Es folgen einzelne Noten. (Z. 91-109).

164 KGA V/6, Nr. 1394 von L. F. Heindorf, wohl November 1802: „Nun gehe ich aber auch in einigen Tagen daran, nachdem ich mit einem schweren Stück Arbeit, der ersten Arbeit über den ganzen Theätet, fertig geworden bin [...]“ (Z. 12-14).

165 KGA V/6, Nr. 1394 (wie oben): „[...] doch ich komme ins Schwatzen, und ich kann Dir etwas Besseres mittheilen, meine neuen reperta im Theätet, wovon einige gar nicht schlecht sind. [...]" Es folgen einzelne Noten. (Z. 57-149).

166 KGA V/6, Nr. 1444 von L. F. Heindorf, 2.3.1803: „Über den Theätet habe ich gar viel zur Erklärung zusammengebracht, so daß ich wohl jetzt einen Commentar darüber schreiben könnte [...]“" (Z. 87-89).

167 KGA V/6, Nr. 1444 (wie oben): „Nach Weihnachten stellte ich unsre Emendationes in Theaetetum versteht sich nur die gewissen, nebst Deiner Erklärung der mathematischen Stelle in eine Epistola Critica zusammen, und schickte sie dem Eichstädt zu beliebigem Gebrauch, um eine Grobheit wieder gut zu machen, da ich ihm mehre [sic] Monate eine Danksagung für die Aufnahme in die societas schuldig geblieben war." (Z. 127-132). Vgl. unten S. 484-489 die Noten und Anmerkungen, jeweils mit App. S. 
Die verlorenen Handschriften sind vermutlich nach Einarbeitung der Korrekturen als Druckvorlagen an den Verlag geschickt worden.

Die Entstehung der oben genannten Handschriften lässt sich aus dem Briefwechsel Schleiermachers rekonstruieren:

1803

- September 3. Heindorf plädiert zum schnelleren Verkauf der Übersetzung dafür, Phaidon, Gorgias u. a. vor den schwierigen Dialogen wie Theaitetos herauszubringen ${ }^{168}$

\section{4}

- Februar 11. Heindorf hat u. a. zum Theaitetos ebenso viel liegen wie zum Gorgias ${ }^{169}$ und bittet Schleiermacher um Mitteilung von Aristoteles-Zitaten $u$. a. aus dem Theaitetos ${ }^{170}$

- März 13. Heindorf hat Kommentar und Noten zum Theaitetos geschrieben ${ }^{171}$

- März 16. Heindorf schickt Schleiermacher „eine kleine Piece“ zum Theaitetos ${ }^{172}$

- Oktober 30. Schleiermacher denkt schon an den dritten Band des Platon ${ }^{173}$

- November 4. Schleiermacher schreibt an Reimer, dass er schon ein wenig am dritten Band arbeitet ${ }^{174}$

168 Siehe oben Anm. 115.

169 KGA V/7, Nr. 1656 von L. F. Heindorf, 11.2.1804: „Wenn nur nicht die andern Dialogen anfangen, mich ebenso zu drücken! Es gehört doch Selbstherrschaft dazu, wenn man soviel vor sich liegen hat, wie ich zum Euthydem, Cratylus und Theätet (ebenso viel gewiß, als zum Gorgias) ganz enthaltsam zu sein." (Z. 6-9).

170 Siehe oben Anm. 118.

171 KGA V/7, Nr. 1684 von L. F. Heindorf, 13.3.1804: „Soviel in Eil, liebster Schleiermacher das hättest Du eher bekommen, wenn ich nicht so tief im Theätet eingegraben gewesen wäre. Ich fing nämlich gleich nach Abschicken der Sachen zum Gorgias einen Commentar zum Theätet an, und fast ist mirs ein Wunder, daß ich in noch nicht vier Wochen das schwere Stück Arbeit so beendigt habe, daß dieses weit über alle meine bisherigen Sachen geht. Fast alles, worüber wir ehemals zweifelten, habe ich nun durch Beispiele erwiesen, und noch ein Duzzend neuer Emendationen gefunden, so daß neben einem Schatz von Sprachanmerkungen doch nun über 160 Ändrungen des Textes kommen. Buttmann hat nun das Ganze." (Z. 1-10).

172 KGA V/7, Nr. 1686 von L. F. Heindorf, 16.3.1804: „Ich schicke Dir hier [...] auch eine kleine Piece zum Theätet. Ist etwas dran?" (Z. 29-31).

173 Siehe oben Anm. 120.

174 Siehe oben Anm. 121. 
- Dezember vor Mitte bis 15. Schleiermacher erwartet, bald nach Neujahr mit der Hauptarbeit beginnen zu können ${ }^{175}$

\section{5}

- Januar 14. Schleiermacher teilt Reimer mit, dass Heindorfs Edition des Gorgias und Theaitetos im Druck ist und er aufgrund dieser seine Übersetzung erarbeiten kann; will den Band im Sommer fertig machen ${ }^{176}$

- Februar Schleiermacher wird vor März von der Übersetzung nichts fertigstellen; der Druck von Heindorfs Edition ist unterbrochen; Spalding steht für die Korrektur nicht zur Verfügung ${ }^{177}$

- März 21. Schleiermacher kündigt Reimer den Gorgias samt Einleitung sowie die Einleitung zum Theaitetos und vielleicht den Anfang des Dialogs an ${ }^{178}$

- März 23. Heindorf schickt die Druckbogen seiner Edition des Gorgias; der Theaitetos könne noch zur Messe fertig werden, die übrigen für den Band geplanten Dialoge erhalten einen eigenen Band $^{179}$

- März/April Schleiermacher teilt Reimer mit, dass u. a. der erste Entwurf des Theaitetos fertig ist und dass bald nach der Messe der Druck beginnen kann ${ }^{180}$

- Ende April/Anfang Mai Schleiermacher schickt Heindorf (wobl) Manuskripte der Platon-Übersetzung und einen Auftrag an Buttmann ${ }^{181}$

\footnotetext{
175 Siehe oben Anm. 122.

176 Siehe oben Anm. 123.

177 Siehe oben Anm. 124.

178 Siehe oben Anm. 125.

179 KGA V/8, Nr. 1939 von L. F. Heindorf, 23.3.1805: „Wäre der Gorgias eher fertig geworden, so hätte ich ihn Dir gewiß schon geschickt. Der Buchdrucker versprach ibn in sechs Wochen zu liefern, und nun ist über ein Vierteljahr daraus geworden, so daß mit genauer Noth noch der Theätet zur Messe fertig werden kann. Da das Buch so angeschwollen ist, so würden ohnehin alle 4 Dialogen nicht in einen Band kommen können; ich will daher nach Ostern noch einen Band fertig machen, enthaltend den Cratylus, Euthydem und Parmenides, in dem ich noch binter unsern Arbeiten her eine kleine Nachlese gefunden habe.” (Z. 28-35).

180 Siehe oben Anm. 127.

181 Siehe oben Anm. 128.
} 
- wobl erste Maihälfte Heindorf kündigt an, Text und Noten für den Theaitetos würden in 14 Tagen fertig sein; zu einer Theaitetosstelle $(174 a)^{182}$

- vor Juli 29. Schleiermacher bittet Heindorf um Übersendung seiner Theaitetos-Edition ${ }^{183}$

- vor Juli 29. Reimer bittet um Fertigstellung des Manuskriptes für den Band 2,1 der Platon-Übersetzung in sechs Wochen ${ }^{184}$

- Juli 29. Schleiermacher findet den von Reimer angesetzten Termin problematisch; ${ }^{185}$ hofft, in 14 Tagen den Theaitetos schicken zu können; wartet auf Heindorfs Arbeit ${ }^{186}$

- Anfang August Reimer bittet mindestens um den Anfang des Theaitetos $^{187}$

- August Heindorf schickt seine vollendete Edition des Theaitetos; bietet seine Hilfe bei der Korrektur der Übersetzung an ${ }^{188}$

182 KGA V/8, Nr. 1963 von L. F. Heindorf, wohl erste Maibälfte 1805: „Zum Theätet soll ich dem Drucker heute das letzte schicken, aber es ist, als lägen Centner auf mir, wenn ich nur etwas an der Arbeit thun soll, daher ich erst in einigen Tagen die letzten Bogen liefern kann. Dann, hoffe ich, soll der Text und die Noten in 14. Tagen fertig sein. Bis so lange also gedulde Dich, liebster.“ (Z. 56-61). „Herzlich danke ich Dir für die Zurechtweisung im Theätet, wo ich das $\sigma \phi \propto \lambda \mu \propto$ nur durch einen Carton tilgen kann. Die Stelle aus dem Euthyphron schützt das aркєĩ vollkommen." (Z. 72-74). Vgl. unten S. 641 App. S (zu Theaitetos 174a).

$183 \mathrm{KGA} \mathrm{V/8,} \mathrm{Nr}$ * 2002 an L. F. Heindorf, vor dem 29.7.1805.

184 Siehe oben Anm. 129.

185 Siehe oben Anm. 130.

186 KGA V/8, Nr. 2004 an G. A. Reimer, 29.7.1805: „Wenn Alles gut geht und Heindorf mir seine Arbeit schnell schikt - geschrieben habe ich ihm schon - so hoffe ich Dir in 14 Tagen den Theätet schikken zu können. Wenn mich Heindorf warten läßt so muß freilich der Theätet so lange liegen bleiben und ich indeß an einen andern Dialog gehn. Unlieb wäre es mir denn ich verlöre immer Zeit dabei." (Z. 27-31).

187 KGA V/8, Nr. 2009 von G. A. Reimer, Anfang August 1805: „Vom Plato schicke mir wo möglich etwas, wenn auch nur den Anfang des Theätet, damit wir etwas weiter kommen." (Z. 13 f.).

188 KGA V/8, Nr. 2010 von L. F. Heindorf, August 1805: „Ich kann Dir etwas froheres, als sonst, liebster Schleiermacher von mir schreiben und endlich einmal etwas tüchtiges schicken, die Vollendung des Theätet. “ (Z. 1-3). „A propos! Wird denn Deine Übersetzung hier gedruckt? Und ich kriege gar nichts davon zu sehen? Nichts zu revidiren oder corrigiren? Du hast mich wohl sonst damit verschonen wollen; aber von nun an werde ich es im eignen Arbeiten sachte angehn lassen, da die Noten zu den 3 Dialogen bis auf die letzte Überarbeitung fertig liegen, und da könnte ich wohl eine Correctur übernehmen, wobei ich vielleicht ein und das andre für Deine Noten bemerkte. Willst Du das, so gieb gleich Ordre dazu an Reimann [gemeint ist Reimer].“ (Z. 73-80). „Ich schicke Dir von den Theätetbogen, was ich 
- August Schleiermacher schickt die Übersetzung und Einleitung des Theaitetos an Reimer 189

- September 6. zum dritten Band fehlt noch die letzte Hälfte des Euthydemos und die Redaktion der Anmerkungen ${ }^{190}$

- September 7. Reimer schickt Aushängebogen; schätzt den Band auf 20 Bogen bis zum Schluss des Theaitetos, 30 Bogen insgesamt; bittet Schleiermacher, möglichst bald die Anmerkungen zu senden; der Band werde spät fertig; kann Korrekturen nicht ganz übernehmen, da er verreist ${ }^{191}$

- vor September 9. Schleiermacher bittet Jösting, Reimer an die Übersendung von Aushängebogen zur Platon-Übersetzung zu erinnern ${ }^{192}$

- September 9. Schleiermacher geht davon aus, dass bis zum Ende des Monats der Druck des dritten Bandes abgeschlossen sein kann; hofft, am übernächsten Tag Aushängebogen des Gorgias und Theaitetos zu erhalten; will die Anmerkungen in spätestens 16 Tagen schicken $^{193}$

- September 14. Schleiermacher will die Anmerkungen in etwa acht Tagen an Reimer schicken; es erscheint ihm sinnlos, Heindorf die Anmerkungen vorher mitzuteilen, da dessen Band noch nicht fertig gedruckt ist ${ }^{194}$

- September 18. Reimer schreibt, der Band werde mehr als 30 Bogen stark; Schleiermacher ist dem Setzer um acht Bogen voraus, die Anmerkungen eilen also nicht; Heindorf wird die Korrektur besorgen und kann dann leicht die Seitenverweise in den Anmerkungen hinzufügen $^{195}$

noch im Hause habe, hoffentlich hast $\mathrm{Du}$ bis dahin alle; wo nicht, so schreibs mir doch gleich mit einer Zeile." (Z. 129-131).

189 KGA V/8, Nr. 2011 an G. A. Reimer, August 1805: „Liebster Freund wenn es nicht nach meiner ganzen Art zu arbeiten eine Unmöglichkeit wäre die Einleitung eher als nach gänzlicher Beendigung der Uebersezung die immer erst beim Mundiren erfolgt fertig zu machen so hättest Du längst etwas vom Theätet erhalten. Nun hast Du ihn ganz, ich habe heute meine Collegia ausgesezt um diese Einleitung halb noch $z u$ entwerfen und ganz zu mundiren und bin fast nicht vom Schreibtisch weggekommen. Lobe mich also immer ein Bischen." (Z. 1-7).

190 Siehe oben Anm. 135.

191 Siehe oben Anm. 136.

192 KGA V/8, Nr. *2028 an Jösting, vor dem 9.9.1805.

193 Siehe oben Anm. 138.

194 Siehe oben Anm. 139.

195 Siehe oben Anm. 140. 
- wohl September 23. Schleiermacher hat die Anmerkungen abgeschlossen und will sie am folgenden Tag schicken ${ }^{196}$

- Oktober 8. Schleiermacher bittet Reimer, ihm bald den Rest des Platon zu senden ${ }^{197}$

- Oktober 25. Schleiermacher hofft, den Rest des Platon zu bekommen; will über manches noch mit Heindorf sprechen ${ }^{198}$

- Oktober 30. Reimer hat Aushängebogen an Schleiermacher geschickt ${ }^{199}$

- November 9. Schleiermacher hat den dritten Band erhalten; er ist zur Messe nicht fertig geworden, aber stärker, als er gedacht hatte $^{200}$

- Dezember 28. Heindorf schreibt, dass bei seiner Korrektur der Anmerkungen die Lemmata nicht immer mit den Worten der gedruckten Übersetzung übereinstimmten und er zudem Anmerkungen mit allgemeinem Bezug selbst zugeordnet hat ${ }^{201}$

\section{Menon}

\subsection{Handschriften aus der Phase der Vorbereitung der Publikation bei Friedrich Frommann}

SN 186 Berlin BBAW, Nachlass F. Schleiermacher NS: $1864^{\circ}$ (Eigenhändige Notizen zum Menon, Alkibiades II., Alkibiades I., Kriton, o. D., $8 \mathrm{Bl}$.). Überschrift auf $f .1^{r}$ : „Aus Wolfs Platonischen Heften." Es folgen die Notizen zum Menon (f. $1^{r}-3^{r}$; am Anfang der ersten Zeile in größerer Schrift als der anschließende Text und unterstrichen: „Meno. “), Alkibiades II. (f. $\left.3^{r}-4^{v}\right)$, Alkibiades I. (f. $\left.4^{v}-7^{r}\right)$, Kriton $\left(7^{r}-8^{v}\right)$. Die Handschrift entstand im oder nach November 1802.202 Die Handschrift ist sorgfältig geschrieben mit wenigen Streichungen und Korrekturen und wenigen, jedoch zunehmend verwendeten Kürzeln und Abbreviaturen. Abgekürzte Autorennamen

196 Siehe oben Anm. 141.

197 Siehe oben Anm. 142.

198 Siehe oben Anm. 143.

199 Siehe oben Anm. 144.

200 Siehe oben Anm. 145.

201 Siehe oben Anm. 146.

202 Vgl. KGA V/6, Nr. 1394 von L. F. Heindorf, wohl November 1802: „Den Aristoteles behalt nur immer auf beliebige Zeit; nicht so lange das Heft, das Spalding in

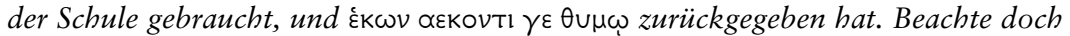
darin die herrliche Einleitung zum Meno, ein kleines Meisterstück historischer Kritik." (Z. 155-159). Vgl. unten Anm. 205 f. und Anm. 216. 
und Werktitel in Literaturzitaten sind belassen. Die Blattzählung ist sekundär.

Die Blätter sind nicht ganz mittig in Spalten geteilt, die recto links, verso rechts beschrieben sind. Die einzelnen Notizen sind mit den Seitenzablen der Ed.Zweibrücken (Bipontina) auf die Stellen des griechischen Textes bezogen; mehrere Notizen zu einer Seite sind mit Gedankenstrich angefügt. Die Seitenangaben sind in der Edition weggelassen und durch die Stephanusseitenzahlen mit dem Zusatz der Seitenzeile in dieser Edition ersetzt. Die mit Gedankenstrich angefügten Notizen werden in der Edition separat und mit eigenem Bezug wiedergegeben.

Die Notizen haben z. T. Eingang gefunden in die Anmerkungen (vgl. W1 Anm.). ${ }^{203}$ Am Rand stehen einige griechische Lemmata und vereinzelte Bemerkungen und Nachträge.

SN 167 Berlin BBAW, Nachlass F. Schleiermacher NS: $1674^{\circ}$ (Eigenhändige Notizen zum Menon und Alkibiades II., o. D., 4 Bl.). Überschrift auf f. $1^{r}$ : „Menon.", darunter Notizen zum Menon (f. $\left.1^{r}-2^{v}\right)$. Die Handschrift entstand nach November 1802 und wohl nach SN 186. ${ }^{204}$ Die Handschrift ist sorgfältig geschrieben mit wenigen Streichungen, Korrekturen und Abbreviaturen, nur im letzten Eintrag ist die Schrift flüchtig mit zablreichen Abbreviaturen. Die für die alten Editionen gängigen Kürzel sind belassen. Die Blattzäblung ist sekundär.

Die Blätter sind nicht ganz mittig in Spalten geteilt, die recto links, verso rechts beschrieben sind. Die einzelnen Notizen sind mit den Seitenzahlen der Ed.Zweibrücken (Bipontina) auf die Stellen des griechischen Textes bezogen. Diese Seitenangaben sind in der Edition weggelassen und durch die Stephanusseitenzahlen mit dem Zusatz der Seitenzeile in dieser Edition ersetzt.

Die Notizen haben z. T. Eingang gefunden in die Anmerkungen (vgl. W1 Anm.). Am Rand einige griechische Lemmata und vereinzelte Bemerkungen und Nachträge.

203 Manche Beobachtungen und Konjekturen Wolfs sind auch bereits 1802 gedruckt erschienen in: F. A. Wolf: Vermischte Schriften und Aufsätze in lateinischer und deutscher Sprache, Halle 1802 [SB 2156]; s. o. Anm. 46.

204 In den Notizen ist Wolfs Heft vorausgesetzt, vermutlich entstanden sie also nach dem Exzerpt aus Wolfs Platonischen Heften (SN 186); vgl. oben Anm. 202. Vgl. außerdem S. 932, Spalte 2 zu 82e, wo auf Heindorfs Brief vom 18.10. oder früher bis 26.10.1802 (KGA V/6, Nr. 1364) angespielt ist. 
Zum Menon sind also folgende Handschriften aus dieser Phase vorhanden:

1. Exzerpt aus Wolfs Platonischen Heften (SN 186)

2. Notizen (SN 167)

Die Entstehung der oben beschriebenen Handschriften lässt sich aus dem Briefwechsel Schleiermachers rekonstruieren:

1802

- Oktober 18. oder früber bis 26. Heindorf erwähnt ein Heft über den Menon von Friedrich August Wolf (Wolfsches Heft), das derzeit bei Spalding sei; berichtet von Wolfs Erklärung der mathematischen Stelle im Menon (vermutlich 87a-b)205

- wohl November Heindorf gibt das Wolfsche Heft, das er inzwischen von Spalding zurückerhalten hat, an Schleiermacher weiter und weist besonders auf die Einleitung zum Menon hin ${ }^{206}$

\subsection{Handschriften zur Vorbereitung des Druckes bei Georg Andreas Reimer}

SN 263/1 Berlin BBAW, Nachlass F. Schleiermacher NS: 263/1 $4^{\circ}$ und $8^{\circ}$ (Briefe Ph. K. Buttmanns an Schleiermacher mit Beilagen). ${ }^{207}$ Der erste Brief (f. $1^{r-4^{v}}$ : KGA V/8, Nr. 1965) enthält Noten zu Platons Menon, die in Spalte 2 zur jeweiligen Stelle nach KGA V/8, ggf. korrigiert aus der Handschrift, wiedergegeben sind. Dabei sind die Abkürzungen in der Regel nicht aufgelöst worden. Der Brief stammt vom 14. Mai 1805.

Diesem Brief war eine Beilage mit Noten zu Menon von L. F. Heindorf beigefügt (1 Blatt $8^{\circ}: f .5^{r}$ Noten, $f .5^{v}$ vacat), die in Spalte 2 zur jeweiligen Stelle aus der Handschrift ediert sind. Dabei sind die Abkürzungen nicht aufgelöst worden.

${ }^{205}$ KGA V/6, Nr. 1364 von L. F. Heindorf, 18.10. oder früher bis 26.10.1802: „Beide Bücher habe ich jetzt nicht bei der Hand, und ebenso wenig das Wolfische Heft über den Meno, das Spalding hat. Daraus will ich Dir nächstens seine Erklärung schicken, die mich aber nie ganz befriedigt hat. Er geht davon aus, daß Meno ganz rudis in der Mathematik sei, folglich hier gar keine Frage aus der eigentlichen Geometrie zu suchen sei." (Z. 139-144).

206 Siehe oben Anm. 202.

207 Die Briefe sind ohne die Beilagen ediert in KGA V/8, Nr. 1965 und Nr. 1967. 
Die einzelnen Notizen sind mit den Stephanusseitenzablen auf die Stellen des griechischen Textes bezogen. Diese Seitenangaben sind in der Edition wiedergegeben und der Bezug zusätzlich durch Stephanusseitenzahl plus Seitenzeile in dieser Edition hergestellt.

SN 514/2 Berlin BBAW, Nachlass F. Schleiermacher NS: 514/2 $8^{\circ}$ (Material zur mathematischen Stelle im Menon, o. D., 2 Bl.). f. $1^{r}$ und f. $2^{r}$ Notizen von A. Boeckh, f. $1^{v}$ Vermerk von Karl Thiel (ediert in KGA V/8, Nr. 1971), darunter eine Notiz Schleiermachers (s. App. ebd.). Boeckhs Notizen sind auf S. 964, Spalte 2 App. S, ediert, vgl. S. 966, Abb. 3a-b.

Zum Menon sind also folgende Handschriften aus dieser Druckphase vorhanden bzw. zu erschließen:

1. Einleitung (verloren)

2. Übersetzung (verloren)

3. Anmerkungen (verloren)

4. Noten Buttmanns und Heindorfs in Briefen an Schleiermacher (SN 263/1)

5. Noten Boeckhs in einem Brief an Schleiermacher (SN 514/2)

Die verlorenen Handschriften sind vermutlich nach Einarbeitung der Korrekturen als Druckvorlagen an den Verlag geschickt worden.

Die Entstehung der oben genannten Handschriften lässt sich aus dem Briefwechsel Schleiermachers rekonstruieren:

\section{4}

- Oktober 30. Schleiermacher denkt schon an den dritten Band des Platon ${ }^{208}$

- November 4. Schleiermacher schreibt an Reimer, dass er schon ein wenig am dritten Band arbeitet ${ }^{209}$

- Dezember vor Mitte bis 15. Schleiermacher erwartet, bald nach Neujabr mit der Hauptarbeit beginnen zu können ${ }^{210}$

208 Siebe oben Anm. 120.

209 Siehe oben Anm. 121.

210 Siehe oben Anm. 122. 
- Dezember 15. Schleiermacher artikuliert seine Abneigung gegen Fr. A. Wolf 211

\section{5}

- Januar 14. Schleiermacher plant die Fertigstellung des dritten Bandes seiner Übersetzung im Sommer ${ }^{212}$

- Februar Schleiermacher wird vor März von der Übersetzung nichts fertigstellen; Spalding steht für die Korrektur nicht zur Verfügung 213

- März/April Schleiermacher arbeitet täglich am Platon; es fehlt bisher noch der halbe Euthydemos und der ganze Menon; erwartet, dass bald nach der Messe der Druck beginnen kann ${ }^{214}$

- Ende April/Anfang Mai Schleiermacher schickt Heindorf (wobl) Manuskripte der Platon-Übersetzung und einen Auftrag an Buttmann ${ }^{215}$

- wohl erste Maihälfte Heindorf und Buttmann bearbeiten Schleiermachers Aufträge zum Menon; sind unzufrieden mit Schleiermachers Deutung der mathematischen Stelle im Menon (86d-87c). Heindorf erinnert Schleiermacher an sein Exzerpt aus dem Wolfschen Heft, das - wie auch Heindorfs Mitschrift aus Wolfs Vorlesung (mit Noten zum Menon) - bei Spalding ist ${ }^{216}$

- Mai 14. Buttmann äußert sich ausfübrlich über die mathematische Stelle im Menon und Schleiermachers Emendationen dazu

211 KGA V/8, Nr. 1880 an C. G. von Brinckmann, 15.12.1804: „Wolf stößt mich doch durch seine Härte und Einseitigkeit so ab, daß nur die Ehrfurcht vor seinem Genie und seiner Virtuosität dem einigermaßen das Gegengewicht halten kann, und daß ich doch kaum das Herz haben werde ihn so wie es sein könnte und sollte für meinen Plato zu benuzen." (Z. 49-53).

212 Siehe oben Anm. 123.

213 Siehe oben Anm. 124.

214 Siehe oben Anm. 127.

215 Siehe oben Anm. 128.

216 KGA V/8, Nr. 1963 von L. F. Heindorf, wohl erste Maibälfte 1805: „Deine Aufträge an Buttmann werde ich morgen mündlich besorgen. Er las mir vorgestern Deine Erklärung der Menonischen Stelle vor, die mich ebenso wenig, als ihn befriedigte, wiewohl ich sie nicht genauer prüfen konnte. Ich werde mir also Deinen Brief an ibn geben lassen. Du hast doch alle Emendationen von Wolf aus dem Hefte ehemals exerpirt? Leider liegt das Heft bei Spalding, sowie auch das Exemplar, was ich bei seinen Vorlesungen hatte, und in das andre habe ich die Emendationen nicht eingetragen, so daß ich, als Buttmann etwas über den Meno für Dich verlangte, fast gar nichts habe finden können. Denn was ich nachher gelegentlich in der Bipontina beigeschrieben, hat gewiß Wolf schon weggenommen." (Z. 62-72). 
(86d-87c) sowie $z u$ anderen Emendationen zum Menon; in einer Beilage fügt Heindorf philologische Noten zum Menon hinzu (SN 263)217

- um Mai Karl Thiel sendet A. Boeckhs Erklärung der mathematischen Stelle im Menon (86d-87c) (SN 514/2)218

- vor Juli 29. Reimer bittet um Fertigstellung des Manuskriptes für den Band 2,1 der Platon-Übersetzung in sechs Wochen ${ }^{219}$

- Juli 29. Schleiermacher findet den von Reimer angesetzten Termin problematisch 220

- August Heindorf bietet seine Hilfe bei der Korrektur der Übersetzung an 221

- August Schleiermacher schickt die Übersetzung und Einleitung des Theaitetos an Reimer zum Setzen. Wenn nur ein Setzer daran arbeiten wird, wird Schleiermacher den Abschluss des Menon-Manuskriptes schaffen, bevor der Satz des Theaitetos fertig ist. ${ }^{222}$

- September 6. zum dritten Band fehlt noch die letzte Hälfte des Euthydemos und die Redaktion der Anmerkungen; der Menon ist also fertig 223

- September 7. Reimer schickt Aushängebogen; der Band wird etwa 30 Bogen stark werden, davon 4 Bogen Menon; bittet Schleiermacher, möglichst bald die Anmerkungen zu senden; kann die Korrekturen nicht ganz übernehmen, da er verreist ${ }^{224}$

217 KGA V/8, Nr. 1965 von Ph. K. Buttmann, 14.5.1805, Z. 1-170. 196-209.

218 KGA V/8, Nr. 1971 von Karl Thiel, um Mai 1805: „Boekh hat sich heute mit dem mathematischen Satze geirrt: er schickt Herrn Professor das Richtigre durch mich" (Z. 1 f.). Vgl. dazu den App.

219 Siehe oben Anm. 129.

220 Siehe oben Anm. 130.

221 Siehe oben Anm. 134.

${ }^{222}$ KGA V/8, Nr. 2011 an G. A. Reimer, August 1805: „Liebster Freund wenn es nicht nach meiner ganzen Art zu arbeiten eine Unmöglichkeit wäre die Einleitung eher als nach gänzlicher Beendigung der Uebersezung die immer erst beim Mundiren erfolgt fertig zu machen so hättest $D u$ längst etwas vom Theätet erhalten. Nun hast Du ihn ganz [...] Wenn ich nur mit e in e $m$ Sezer zu thun habe so garantire ich Dir den Menon ehe der Theätet fertig ist; aber zweie sind auch dem Herkules zu viel." (Z. 1-9).

223 Siehe oben Anm. 135.

${ }^{224}$ KGA V/8, Nr. 2027 von G. A. Reimer, 7.9.1805: „Hier liebster Freund, die Aushängebogen 6 und 9-13; doch habe ich eben 16 zur Correctur erhalten. Bis zum Schluß des Theätet wird dieser Band 20 Bogen betragen, und der Menon mag etwa noch vier geben; da dann noch ein Dialog folgt und die Anmerkungen so wird dieser Band wohl einige dreißig Bogen stark werden. Einen Transport der Aushängebogen sende ich dann noch in 8 Tagen und werde Auftrag geben, daß man Dir die übrigen von Zeit zu Zeit übersende. Sei Du dann aber ja so gut die Anmerkun- 
- September 9. Schleiermacher geht davon aus, dass bis zum Ende des Monats der Druck des dritten Bandes abgeschlossen sein kann; will die Anmerkungen in spätestens 16 Tagen schicken;225 bittet darum, Heindorf die Anmerkungen besonders zum Menon und Euthydemos korrigieren zu lassen 226

- September 14. Schleiermacher will die Anmerkungen in etwa acht Tagen an Reimer schicken; es erscheint ihm sinnlos, Heindorf die Anmerkungen vorher mitzuteilen, da dessen Band noch nicht fertig gedruckt ist ${ }^{227}$

- September 18. Reimer schreibt, der Band werde mehr als 30 Bogen stark; Schleiermacher ist dem Setzer um acht Bogen voraus, die Anmerkungen eilen also nicht; Heindorf wird die Korrektur besorgen und kann dann leicht die Seitenverweise in den Anmerkungen hinzufügen 228

- wobl September 23. Schleiermacher hat die Anmerkungen abgeschlossen und will sie am folgenden Tag schicken 229

- Oktober 8. Schleiermacher hat von Heindorf erfabren, dass der Druck des Menon noch nicht fertig ist; Heindorf sollte noch eine Anmerkung hinzufügen und hierzu das Manuskript erhalten; ${ }^{230}$ Schleiermacher bittet Reimer, ihm bald den Rest des Platon zu senden ${ }^{231}$

gen, so viel möglich zu fördern; schicke allenfalls den Rest zur reitenden Post. Ohnehin wird der Band spät genug fertig [...] Dann thut es mir auch leid, daß ich die Correcturen nicht ganz übernehmen, und die Versendung nicht besorgen kann, meiner Reise wegen." (Z. 2-14).

225 Siehe oben Anm. 138.

${ }^{226}$ KGA V/8, Nr. 2031 an G. A. Reimer, 9.9.1805: „Von den Anmerkungen, besonders denen zum Menon und Euthydemos wäre es mir aber sebr lieb, wenn er [sc. Heindorfl sie bei Gelegenheit einer Revision vor dem Drukk sähe, und ich bitte Dich es zu veranstalten wenn es obne zu großen Aufenthalt geschehen kann." (Z. 16-20).

227 Siehe oben Anm. 139.

228 Siehe oben Anm. 140.

229 Siehe oben Anm. 141.

230 KGA V/8, Nr. 2045 an G. A. Reimer, 8.10.1805: „Wie sauer es uns in Berlin geworden ist irgend eine Nachricht vom Platon einzuziehen und nur die Aushängebogen zu verschaffen wird Dir Jösting wol auch gesagt haben. Wie weit der Druk war, nemlich noch nicht den Menon zu Ende habe ich von Heindorf erfahren. Indeß da wie er mir sagte täglich ein Bogen abgesezt würde so hoffe ich wird jezt alles beendigt sein. Ein Karton hatte ich noch mit Heindorf verabredet, und eine Anmerkung sollte er hinzufügen, zu welchem Behuf ihm hoffentlich das Manuscript wird ausgehändigt worden sein." (Z. 35-42).

231 Siehe oben Anm. 142. 
- Oktober 25. Schleiermacher hofft, den Rest des Platon zu bekommen; will über manches noch mit Heindorf sprechen ${ }^{232}$

- Oktober 30. Reimer hat Aushängebogen an Schleiermacher geschickt 233

- November 9. Schleiermacher hat den dritten Band erhalten; er ist zur Messe nicht fertig geworden, aber stärker, als er gedacht hatte 234

- Dezember 28. Heindorf schreibt, dass bei seiner Korrektur der Anmerkungen die Lemmata nicht immer mit den Worten der gedruckten Übersetzung übereinstimmten und er zudem Anmerkungen mit allgemeinem Bezug selbst zugeordnet hat ${ }^{235}$

\section{Euthydemos}

\subsection{Handschriften aus der Phase der Vorbereitung der Publikation bei Friedrich Frommann}

SN 168 Berlin BBAW, Nachlass F. Schleiermacher NS: $1684^{\circ}$ (Eigenhändige Notizen zum Euthydemos, o. D., 2 Bl. unfoliiert). Überschrift auf f. 1' ${ }^{r}$ : „Euthydemus“, darunter „Flüchtige Lesung“, darunter Notizen zum Euthydemos (f. $\left.1^{r}-2^{r}\right)$. Die Handschrift entstand vermutlich 1801/1802.236 Zahlreiche gängige Kürzel und spontane Abbreviaturen. Abkürzungen in griechischen Lemmata und Zitaten aus dem Platontext sind ohne weitere Erklärung im Text belassen. Abgekürzte Namen aus dem Dialog sind ebenfalls belassen.

Die Blätter sind in der Mitte in Spalten geteilt, die recto links, verso rechts mit den Notizen beschrieben sind.

Die einzelnen Notizen sind mit den Seitenzablen der Ed.Zweibrücken (Bipontina) auf die Stellen des griechischen Textes bezogen. Diese Seitenangaben sind in der Edition weggelassen und durch die Stephanusseitenzahlen mit dem Zusatz der Seitenzeile in dieser Edition ersetzt.

232 Siehe oben Anm. 143.

233 Siehe oben Anm. 144.

234 Siehe oben Anm. 145.

235 Siehe oben Anm. 146.

236 Vgl. Schleiermachers Notizen „Zum Platon“ (Vermutlich 1801-1803), KGA I/3, S. 353, Notat 28, das wohl vor Februar 1802 entstand, vgl. S. CI. Vgl. auch den Brief von F. Schlegel, 25.2.1802: KGA V/5, Nr. 1170, 36 f., mit dem Brief an A. Boeckh, wohl Ende April bis 18.6.1808: KGA V/10, Nr. 2701, 88-90, sowie unten Anm. 238. 
Die Notizen haben z. T. Eingang gefunden in die Anmerkungen (vgl. W' Anm.). Am Rand nur ein einziger nachträglicher Verweis.

Zum Euthydemos ist also nur eine Handschrift aus dieser Phase vorhanden:

\section{Notizen (SN 168)}

Die Entstehung der oben beschriebenen Handschrift lässt sich aus dem Briefwechsel Schleiermachers rekonstruieren:

1801

- Oktober 26. F. Schlegel plant den Euthydemos in den zweiten Teil der gemeinsamen Platon-Übersetzung aufzunehmen, wenn noch Platz ist ${ }^{237}$

- November 16. Schlegel schiebt den Euthydemos auf, empfiehlt ibn Schleiermacher; Schleiermacher und Heindorf haben die Verwandtschaft des Euthydemos richtig bestimmt ${ }^{238}$

1802

- November 14. Schleiermacher stimmt mit Schlegels Ansichten über die für den zweiten und dritten Band geplanten Dialoge zum großen Teil nicht überein ${ }^{239}$

1803

- März 2. Heindorf meldet 30 Emendationen im Euthydemos ${ }^{240}$

${ }^{237}$ KGA V/5, Nr. 1115 von F. Schlegel, 26.10.1801: „Ferner bitte ich, wähle nun zum 2ten Theil. Nach meiner Ordnung kommen - Euthyphron - Theages - Krito Phaedon - und dann wenn noch Raum ist der Euthydemus -" (Z. 36-38 = KFSA 25, Nr. 198, S. 300 f.); vgl. KGA V/4, Nr. 993, Z. 84-119.

${ }^{238}$ KGA V/5, Nr. 1122 von F. Schlegel, 16.11.1801: „Der Euthydem kömmt noch nicht so bald; es ist natürlich daß Du auf ihn ein besondres Augenmerk hast. [...] Dem Euthydemus habt ihr, vortrefliche Männer, seine Verwandtschaft sehr richtig bestimmt. " (Z. 25-27 und Z. 42-44 = KFSA 25, Nr. 203, S. 307).

239 KGA V/6, Nr. 1377 an H. Herz, 14.11.1802: s. o. Anm. 17.

${ }^{240}$ KGA V/6, Nr. 1444 von L. F. Heindorf, 2.3.1803: „Im Euthydem habe ich wohl 30 grobe Febler gefunden" (Z. 92 f.). 


\subsection{Handschriften zur Vorbereitung des Druckes bei Georg Andreas Reimer}

Handschriftliches Material aus dieser Druckphase ist nicht erhalten, doch lassen sich folgende Handschriften erschließen:

1. Einleitung (verloren)

2. Übersetzung (verloren)

3. Anmerkungen (verloren)

Die verlorenen Handschriften sind vermutlich nach Einarbeitung der Korrekturen als Druckvorlagen an den Verlag geschickt worden.

Die Entstehung der oben genannten Handschriften lässt sich aus dem Briefwechsel Schleiermachers rekonstruieren:

\section{3}

- Dezember 30. Heindorf benötigt für die Bearbeitung des Gorgias die Edition von Routh, die auch den Euthydemos enthält ${ }^{241}$

\section{4}

- Februar 11. Heindorf hat u. a. zum Euthydemos ebenso viel liegen wie zum Gorgias ${ }^{242}$ und bittet Schleiermacher um Mitteilung von Aristoteles-Zitaten $u$. a. aus dem Euthydemos; ${ }^{243}$ er lobt die Ausgabe von Routh 244

- März 13. Heindorf will bald den Euthydemos bearbeiten ${ }^{245}$

- März 16. Heindorf hofft, Kratylos und Euthydemos noch zu beenden ${ }^{246}$

241 Siehe oben Anm. 116.

242 Siehe oben Anm. 169.

243 Siehe oben Anm. 118.

${ }^{244}$ KGA V/7, Nr. 1656 von L. F. Heindorf, 11.2.1804: „Den Routh habe ich erst bei dieser Fortsetzung benutzen können; so ganz übel ist er nicht und die 5 rth $12 \mathrm{gr}$ doch werth." (Z. 75-77).

${ }^{245}$ KGA V/7, Nr. 1684 von L. F. Heindorf, 13.3.1804: „[...] und so denke ich bald den Cratylus über Seite zu bringen, [...] dann ist der kleine Euthydem noch übrig, und dann wenn ich auch den Druck nicht erlebte, ich habe dann doch etwas Tüchtiges gethan, und mein Name ist ewig geworden." (Z. 11-16).

${ }^{246}$ KGA V/7, Nr. 1686 von L. F. Heindorf, 16.3.1804: „[...] wünsche mir Kraft, daß ich noch den Kratylus und Euthydem fertig kriege." (Z. 50 f.). 
- Oktober 30. Schleiermacher denkt schon an den dritten Band 247 - November 4. Schleiermacher schreibt an Reimer, dass er schon ein wenig am dritten Band arbeitet ${ }^{248}$

- Dezember vor Mitte bis 15. Schleiermacher erwartet, bald nach Neujabr mit der Hauptarbeit beginnen zu können ${ }^{249}$

\section{5}

- Januar 14. Schleiermacher plant die Fertigstellung des dritten Bandes seiner Übersetzung im Sommer 250

- Februar Schleiermacher wird vor März von der Übersetzung nichts fertigstellen; Spalding steht für die Korrektur nicht zur Verfügung 251

- März 23. Heindorf will nach Ostern einen Band mit den Dialogen Kratylos, Euthydemos und Parmenides herausgeben; will dazu im Sommer Kratylos und Euthydemos noch einmal nach Buttmanns Erinnerungen durcharbeiten ${ }^{252}$

- März/April Schleiermacher arbeitet täglich am Platon; es fehlt bisher noch der halbe Euthydemos und der ganze Menon; erwartet, dass bald nach der Messe der Druck beginnen kann ${ }^{253}$

- Ende April/Anfang Mai Schleiermacher schickt Heindorf (wobl) Manuskripte der Platon-Übersetzung und einen Auftrag an Buttmann ${ }^{254}$

- vor Juli 29. Reimer bittet um Fertigstellung des Manuskriptes für den Band 2,1 der Platon-Übersetzung in sechs Wochen ${ }^{255}$

- Juli 29. Schleiermacher findet den von Reimer angesetzten Termin problematisch ${ }^{256}$

247 Siehe oben Anm. 120.

248 Siehe oben Anm. 121.

249 Siehe oben Anm. 122.

250 Siehe oben Anm. 123.

251 Siehe oben Anm. 124.

252 KGA V/8, Nr. 1939 von L. F. Heindorf, 23.3.1805: „Da das Buch so angeschwollen ist, so würden ohnehin alle 4 Dialogen nicht in einen Band kommen können; ich will daher nach Ostern noch einen Band fertig machen, enthaltend den Cratylus, Euthydem und Parmenides, in dem ich noch hinter unsern Arbeiten her eine kleine Nachlese gefunden habe." (Z. 31-35). „Desto mehr Arbeit sehe ich aber nun im Sommer vor mir, da ich den Cratylus und Euthydem nach Buttmanns Erinnerungen noch einmal durcharbeiten muss. " (Z. 72-74).

253 Siehe oben Anm. 127.

254 Siehe oben Anm. 128.

255 Siehe oben Anm. 129.

256 Siehe oben Anm. 130. 
- August Heindorf bietet seine Hilfe bei der Korrektur der Übersetzung an ${ }^{257}$

- September 6. zum dritten Band fehlt noch die letzte Hälfte des Euthydemos und die Redaktion der Anmerkungen 258

- September 7. Reimer schickt Aushängebogen; schätzt den Band auf 20 Bogen bis zum Schluss des Theaitetos, 30 Bogen insgesamt; bittet Schleiermacher, möglichst bald die Anmerkungen zu senden; der Band werde spät fertig; kann Korrekturen nicht ganz übernehmen, da er verreist 259

- September 9. Schleiermacher geht davon aus, dass bis zum Ende des Monats der Druck des dritten Bandes abgeschlossen sein kann; will die Anmerkungen in spätestens 16 Tagen schicken; ${ }^{260}$ bittet darum, Heindorf die Anmerkungen besonders zum Menon und Euthydemos korrigieren zu lassen ${ }^{261}$

- September 14. Schleiermacher schickt den Euthydemos an Reimer; will die Anmerkungen in etwa acht Tagen schicken; hat überlegt, den Euthydemos in den nächsten Band zu verschieben, diese Idee jedoch wieder verworfen; es erscheint ihm sinnlos, Heindorf die Anmerkungen vorher mitzuteilen, da dessen Band noch nicht fertig gedruckt ist ${ }^{262}$

- September 18. Reimer schreibt, der Band werde mehr als 30 Bogen stark; Schleiermacher ist dem Setzer um acht Bogen voraus, die Anmerkungen eilen also nicht; Heindorf wird die Korrektur besorgen

\footnotetext{
257 Siehe oben Anm. 134.

258 Siehe oben Anm. 135.

259 Siehe oben Anm. 136.

260 Siehe oben Anm. 138.

261 Siehe oben Anm. 226.

${ }^{262}$ KGA V/8, Nr. 2033 an G. A. Reimer, 14.9.1805: „Hier lieber Freund schikke ich Dir den Euthydemos einen Posttag eher als ich ihn Dir versprochen. Die Anmerkungen sollen wie ich zuversichtlich hoffe über acht Tage nachfolgen: denn sie sind schon fast ganz ausgearbeitet. Nach Empfang Deines Briefes berathschlagte ich ob es nicht möglich wäre den Euthydemos wenn der Band so verhältnißmäßig stark werden sollte auf den nächsten zu versparen. Allein dann hätte ich entweder 2 Dialogen trennen müssen die ganz unmittelbar zusammengehören oder den Zweiten Theil in 4 Bände abtheilen müssen die dann doch zum Theil noch kleiner geworden wären, und das schien mir gar nicht rathsam. [...] Ich glaubte bis Ende Theätetos 17 Bogen und die beiden andern Dialogen 6. Die Anmerkungen können höchstens 3 bis 4 Bogen geben. Werde ich bis Freitag fertig so schikke ich sie mit der Reitpost, es macht für den Drukk gewiß zwei volle Tage Unterschied. Die Anmerkungen Heindorf vorher mitzutheilen gebe ich auf; es ist auch nicht wesentlich da sein Buch immer noch nicht fertig gedrukt ist" (Z. 3-18).
} 
und kann dann leicht die Seitenverweise in den Anmerkungen hinzufügen $^{263}$

- wohl September 23. Schleiermacher hat die Anmerkungen abgeschlossen und will sie am folgenden Tag schicken ${ }^{264}$

- Oktober 8. Schleiermacher hat von Heindorf erfahren, dass der Druck des Menon noch nicht fertig ist; Heindorf sollte noch eine Anmerkung hinzufügen und hierzu das Manuskript erhalten; ${ }^{265}$ Schleiermacher bittet Reimer, ihm bald den Rest des Platon zu senden ${ }^{266}$

- Oktober 25. Schleiermacher hofft, den Rest des Platon zu bekommen; will über manches noch mit Heindorf sprechen ${ }^{267}$

- Oktober 30. Reimer hat Aushängebogen an Schleiermacher geschickt ${ }^{268}$

- November 9. Schleiermacher hat den dritten Band erhalten; er ist zur Messe nicht fertig geworden, aber stärker, als er gedacht hatte $^{269}$

- Dezember 28. Heindorf hat seine Edition u. a. des Euthydemos fertig; ${ }^{270}$ schreibt, dass bei seiner Korrektur von Schleiermachers Anmerkungen zur Übersetzung die Lemmata nicht immer mit den Worten der gedruckten Übersetzung übereinstimmten und er zudem Anmerkungen mit allgemeinem Bezug selbst zugeordnet hat ${ }^{271}$

\section{Editorischer Bericht}

Die Bände IV/3-8, die die Platon-Übersetzung Schleiermachers enthalten, sind nach den Editorischen Grundsätzen für die IV. Abteilung gestaltet. ${ }^{272}$ Die besonderen Gegebenheiten der hier veröffentlichten Texte machen jedoch zusätzliche Regelungen erforderlich.

\footnotetext{
263 Siebe oben Anm. 140.

264 Siehe oben Anm. 141.

265 Siehe oben Anm. 230.

266 Siehe oben Anm. 142.

267 Siehe oben Anm. 143.

268 Siehe oben Anm. 144.

269 Siehe oben Anm. 145.

270 KGA V/8, Nr. 2104 von L. F. Heindorf, 28.12.1805: „Da ich die Drucksachen zum Parmenides und Euthydem schon ganz fertig hatte [...] " (Z. 39 f.).

271 Siehe oben Anm. 146.

272 S. o. S. VIII-XIV.
} 
1. Textgestaltung und zugehörige editorische Informationen

\section{A. Allgemeine Regeln}

Die für die eigenständigen Texte Schleiermachers und die einzelnen Platon-Dialoge jeweils unterschiedliche Überlieferungslage sowie die jeweilige Relevanz der Überlieferung machen in der Edition differenzierte Präsentationsformen nötig.

Die eigenständigen Texte Schleiermachers (die Einleitungen sowie die Titelblätter) sind in der Fassung der zweiten Auflage als der Auflage letzter Hand mit ibren Anmerkungen ediert, wobei Varianten der ersten Auflage im textkritischen Apparat (T) dokumentiert sind. Es ist jeweils ein Sachapparat (S) beigegeben. Sofern handschriftliche Vorarbeiten vorhanden sind (das Exzerpt aus Wolfs Platonischen Heften zur Menon-Einleitung), sind diese jeweils an einschlägiger Stelle der Einleitung als Apparat dem edierten Text beigefügt und ediert. Die Entstehungsvarianten sind in einem eigenen textkritischen Apparat (T) dokumentiert. Ein eigener Sachapparat (S) ist beigegeben.

Die Übersetzung der Platon-Dialoge selbst ist grundsätzlich in vier parallelen Spalten ediert: Spalte 1: griechischer Text der der Übersetzung zugrundeliegenden Vorlage; Spalte 2: handschriftliche Vorarbeiten Schleiermachers (zum Theaitetos, Menon und Euthydemos) und zusätzlich ggf. im Zusammenhang mit der Genese der Übersetzung entstandene Noten von Heindorf, Buttmann u. a.; Spalte 3: erste Auflage der gedruckten Übersetzung samt Anmerkungen; Spalte 4: zweite Auflage der gedruckten Übersetzung samt Anmerkungen. Spätere Auflagen oder Ausgaben werden nicht verzeichnet, da sie nach Schleiermachers Tod nicht von ihm autorisiert sind.

Die Anmerkungen, die in den gedruckten Texten der 1. und 2. Auflage in einem eigenen Anmerkungsteil am Ende des Bandes stehen und lediglich durch Angabe der Seite und Zeile mit gesperrtem Kurzzitat auf den erläuterten Übersetzungstext verweisen, obne dass dort auf die Existenz der Anmerkung verwiesen ist, sind in der Edition als Fußnoten an den Text gebunden, den sie erläutern, und unter den Text gestellt.

Der ersten Spalte ist nur ein Apparat beigegeben, der alle für die Übersetzung in ihren verschiedenen Bearbeitungsstufen relevanten Varianten, Konjekturen etc. bietet. In der zweiten Spalte ist ein Apparat (T) sowie ein Sachapparat (S) (ggf. differenziert) auf die präsentierten Vorarbeiten und Noten Schleiermachers $u$. a. bezogen. Der dritten und vierten Spalte ist je ein auf den Text oder Schleiermachers Anmerkungen bezogener Apparat (T) sowie ein Sachapparat (S) beigegeben. 
Sachinformationen (Apparat S), die im Prinzip zu jeder der drei Spalten in identischer Weise gegeben werden müssten, werden in der Regel nur an einem Ort gegeben, auf den dann von den beiden anderen verwiesen wird.

Die Grundlage des edierten Textes ist jeweils am Anfang im (textkritischen) Apparat dokumentiert und ggf. beschrieben. Daneben sind die Quellen der angefübrten Varianten genannt.

Zeichensetzung. Hinsichtlich der Zeichensetzung ist die Sparsamkeit, mit der Schleiermacher auch ausgedehnte Satzperioden nur durch wenige Interpunktionszeichen gliedert, durchaus programmatisch gewollt. ${ }^{273}$ Entsprechend werden im gedruckten Text keine Kommata und Doppelpunkte ergänzt. Dies gilt auch für die Fälle, in denen Schleiermacher in den Handschriften Übersetzungen in seinen eigenen fortlaufenden Text integriert.

Schreibweise. In die besonders in den Handschriften teilweise sehr schwankend gebrauchte Groß- und Kleinschreibung von Pronomina, Zahlwörtern, substantivierten Adjektiven und Anreden wird in der Regel nicht eingegriffen. Zweifelsfälle werden nach Kontext entschieden.

Die in den Handschriften bisweilen schwer von $\beta$ unterscheidbare Kombination von langem und kurzem s ist wie die Kombination von langem und kurzem s in den Druckausgaben als $\beta$ ediert.

Griechische Wörter sind in der Regel in der Schreibweise der jeweiligen Vorlage übernommen. Feblende Akzente und diakritische

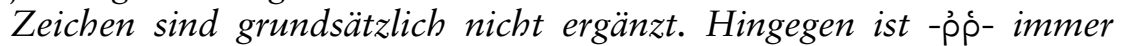
ohne Spiritus wiedergegeben. Zitate aus französischen Quellen in den Handschriften werden in der von Schleiermacher niedergeschriebenen Form wiedergegeben; feblende Zeichensetzung und Akzente sind nicht ergänzt sowie Groß-und Kleinschreibung nicht korrigiert.

In der zweiten Auflage (1818) ist eine (allerdings inkonsequente) Veränderung der Wortschreibung von „k“,,$c k$ "zu „kk" sowie von „ß“ $z u$ „ss“ $z u$ beobachten. Bei den eigenständigen Texten Schleiermachers, die nach der zweiten Auflage ediert sind und bei denen die Varianten der ersten Auflage im textkritischen Apparat mitgeteilt werden, werden die Veränderungen der Schreibweise jeweils einzeln an der Belegstelle nachgewiesen.

Die Veränderung der Schreibweise der griechischen Eigennamen von - $\ddot{a}$ - bzw. -ae- in der ersten Auflage zu-ai-in der zweiten Auflage

273 Vgl. KGA IV/3, S. XXXIV mit Anm. 112+113. 
ist (fast) konsequent durchgeführt z. B. bei Chaerephon/Chairephon, Phädros/Phaidros, Theätetos/Theaitetos, Phädon/Phaidon, Timäos/ Timaios. ${ }^{274}$ Bei den eigenständigen Texten Schleiermachers, die nach der zweiten Auflage ediert sind und bei denen die Varianten der ersten Auflage im textkritischen Apparat mitgeteilt werden, werden die Veränderungen der Schreibweise jeweils einzeln an der Belegstelle nachgewiesen oder bei gehäuftem Vorkommen in einem Abschnitt beim ersten Vorkommen zusammengefasst.

\section{B. Besondere Regeln für Schleiermachers Manuskripte}

Abbreviaturen. In Schleiermachers Manuskripten sind Wörter und Wortbestandteile häufig durch Kurzformen geschrieben, die auch kombiniert vorliegen können. Folgende Kurzformen und Abkürzungen werden stillschweigend in der Regel ohne textkritischen Einzelnachweis am Ort aufgelöst:

\begin{tabular}{|c|c|c|c|}
\hline $\begin{array}{l}\hat{\mathrm{a}}, \hat{\mathrm{a}} \\
\mathrm{ab}\end{array}$ & $\begin{array}{l}\text { auch } \\
\text { aber }\end{array}$ & $\begin{array}{l}\mathrm{f},-\mathrm{f}, \mathrm{f}- \\
\Theta, \Theta \mathrm{s}\end{array}$ & $\begin{array}{l}\text { auf, -auf, auf- } \\
\text { Gott, Gott(e)s }\end{array}$ \\
\hline $6,-6,6-$ & $\begin{array}{l}\text { aus, -aus, aus- } \\
\text { Beoriff }\end{array}$ & $-g$ & -ung (mit \\
\hline & Begrift & $\mathrm{Hd} \mathrm{Hnd} / \mathrm{s}$ ) & Endungen) \\
\hline (-) & $\begin{array}{l}\text { der, die, das, } \\
\text { den, dem }\end{array}$ & $\begin{array}{l}\text { Hndf(s), } \\
\text { Heind, Heindf }\end{array}$ & Hentarts) \\
\hline dadh & dadurch & h- & her- \\
\hline df & darauf & $-h t$ & -heit (mit \\
\hline -dg & -dung & & Endungen) \\
\hline in & $\begin{array}{l}\text { durch } \\
\text { den }\end{array}$ & $\begin{array}{l}\mathrm{K}, \mathrm{K}_{\mathrm{l}} \\
\mathrm{k}, \mathrm{k}^{\mathrm{e}}, \mathrm{k}^{\mathrm{n}}, \mathrm{k}^{\mathrm{r}}\end{array}$ & $\begin{array}{l}\text { koi } \\
\text { kein, keine, }\end{array}$ \\
\hline $\mathrm{dr}$ & der & & keinen, keiner \\
\hline $\begin{array}{l}\text { ds } \\
\text { dfe }\end{array}$ & $\begin{array}{l}\text { das, dies } \\
\text { diese }\end{array}$ & $-k t$ & $\begin{array}{l}\text {-keit (mit } \\
\text { Endungen) }\end{array}$ \\
\hline dfm & diesem & $-l$ & -lich (mit \\
\hline dfn & diesen & & Endungen) \\
\hline dfr & dieser & $-\mathrm{l}^{\mathrm{e}},-\mathrm{-l}^{\mathrm{n}}$ & -liche, -lichen \\
\hline & dieses & $\mathrm{m}, \mathrm{m}$ & $\operatorname{man}$ \\
\hline ß & $\mathrm{da} ß$ & $\dot{\mathrm{o}}, \mathrm{o}, \mathrm{o}$ & nicht \\
\hline & $\begin{array}{l}\text {-en, -em, -er } \\
\text { entweder }\end{array}$ & $\dot{\text { os }}$ & nichts \\
\hline
\end{tabular}

274 Vgl. KGA IV/3, S. XXXIII f. mit Anm. 109-111. - Vgl. analog z. B. die Änderung von Euklides in Eukleides. 
$f$

sd

sne, snm

sond

$\mathrm{u}, \mathrm{u}$.

üb, -üb, üb-, Ueb., Ueb sich

sind

seine, seinem

sondern

und

über, -über,

über-, Ueber $\mathrm{v}, \mathrm{vn}$

V-, v-

$\mathrm{vr}$

W, Wf

Wh.

$\mathrm{z}$ von, vom

Ver-, ver-

vor

Wolf

Wahrheit

zu, zur, zum

\section{Sachapparat}

Die Sachapparate machen Angaben zu den von Schleiermacher in den Einleitungen und Anmerkungen erwähnten, nicht aus sich heraus verständlichen Personen und Sachverhalten. Sie erläutern nicht die übersetzten Platontexte. Des weiteren werden Schleiermachers Verweise auf antike Textstellen und Sekundärliteratur bibliographisch aufgelöst und nach Möglichkeit die von Schleiermacher verwendeten Ausgaben ermittelt. Schließlich wird die unmittelbare Auseinandersetzung der Zeitgenossen mit den Übersetzungen Schleiermachers, mitunter auch mit seinen textkritischen und interpretatorischen Vorschlägen, in Rezensionen und anderen zeitnahen Publikationen dokumentiert, vorrangig wo dann Reaktionen Schleiermachers darauf aus Veränderungen zur zweiten Auflage hin deutlich sind.

\section{Druckgestaltung}

\section{A. Seitenaufbau}

Entsprechend den allgemeinen Regeln (s. o. 1.A.) werden die verschiedenen Texte geboten. Dabei sind zwei verschiedene Formen verwendet: fortlaufende Folge von Einzelseiten oder auf Doppelseiten Synopsen von drei oder vier parallelen Texten.

a. Satzspiegel. In der dritten und vierten Spalte werden untereinander angeordnet: Text des Originals, als nummerierte Fußnoten die Anmerkungen Schleiermachers, die in den Originalen mit der in der Edition weggelassenen Angabe der jeweiligen Bezugsstelle in einem eigenen Anmerkungsteil hinten hinzugefügt sind, textkritischer Apparat (T), Sachapparat (S). In der zweiten Spalte sind, sofern erhalten, handschriftliche Vorarbeiten ediert. Hier sind untereinander angeordnet: verschiedene Vorarbeiten Schleiermachers, ggf. Noten 
Heindorfs und Buttmanns u. a., textkritischer Apparat (T), Sachapparat (S).

Zur besseren Orientierung ist auf jeder Seite der textkritische Apparat mit T bzw. T Anm. oder in der zweiten Spalte T Noten o. ä. und der Sachapparat mit $S$ bzw. S Anm. oder S Noten o. ä. gekennzeichnet.

b. Die Beziehung der Apparate auf den Text erfolgt durch Angabe der Seitenzeile (s. o. S. XII). Die Beziehung der Apparate auf die Anmerkungen erfolgt durch den Verweis auf die Anmerkungszahl, ggf. mit Angabe der Seitenzeile und Bezugswort. Die handschriftlichen Vorarbeiten Schleiermachers und Noten Heindorfs und Buttmanns sind durch Angabe der Stephanusseiten und der Seitenzeile des griechischen Textes (Spalte 1) zugeordnet.

\section{B. Gestaltungsregeln}

b. Die Seitenzählung wird jeweils auf dem Außenrand angegeben (s. o. S. XIII), und zwar zum griechischen Text generell die Stephanusseitenzählung mit Untergliederung, nicht die Seitenzählung der jeweils benutzten Ausgabe, zu den Handschriften die Blattzäblung von anderer Hand (s. o. die Beschreibungen der einzelnen Handschriften), zu den Druckfassungen die Seitenzählung beider Auflagen, wobei auch für unpaginierte Seiten des Druckes stillschweigend Seitenzahlen am Rand der Edition angegeben sind.

\section{Einleitung und Verzeichnisse}

\section{Verzeichnisse}

Der Band enthält zusätzlich zu den Verzeichnissen der Zeichen und Abkürzungen, der Literatur, der Personen (mit Werken) und Orte, ein Verzeichnis der Sachen, ein Verzeichnis griechischer Wörter und ein Verzeichnis von Schleiermachers eigenen Konjekturen zum griechischen Text. Ein Verzeichnis der Abbildungen schließt den Band ab.

Das Verzeichnis der Sachen führt Gegenstände und Begriffe an, die in der wissenschaftlichen Diskussion über Platon und die Platon-Übersetzung von einiger Wichtigkeit waren oder immer noch sind. 
Das Verzeichnis griechischer Wörter fübrt diejenigen Wörter an, die als solche besprochen werden.

Das Verzeichnis von Schleiermachers eigenen Konjekturen zum griechischen Platon-Text bietet eine Liste der Platon-Stellen, zu denen es originäre, d. h. eigene Konjekturen Schleiermachers zum griechischen Platon-Text gibt.

Das Verzeichnis der Abbildungen weist die Provenienz der exemplarisch zur Illustration gegebenen Abbildungen nach.

\section{Spezifische Verfahrensweisen bei den einzelnen Dialogen}

Die Übersetzungen der Dialoge Platons sind nach dem oben beschriebenen Vier-Spalten-Prinzip ediert. Da zu den einzelnen Dialogen einerseits verschiedene griechische Ausgaben als Vorlage benutzt worden sind, andererseits Handschriften von unterschiedlicher Art und aus verschiedenen Entstehungszusammenhängen vorhanden sind, wird bei jedem Dialog im Rabmen der editorischen Regeln und Grundsätze in einzelnen Punkten in spezifischer Weise verfahren.

\section{A. Gorgias}

Der griechische Text (Spalte 1) ist aus der Ausgabe von Heindorf (1805) gegeben, deren verschiedene Entstehungsstufen Schleiermacher benutzt hat, deren Erscheinen im Oktober 1805 jedoch für die Erarbeitung der Übersetzung zu spät kam. ${ }^{275}$ Die dort am Rand mitgeführte Stephanusseitenzählung wird auf dem Außenrand angegeben. Nicht angegeben ist Heindorfs Seiten- und Kapitelzählung. Da Heindorf gegenüber den Vorgängereditionen Orthographica, Akzentsetzung und Interpunktion weitgehend normalisiert und modernisiert hat, sind Fehler und orthographische Besonderheiten (z. B. Endsigma im Wortinneren, Spiritus über -p’p-) in der Regel stillschweigend korrigiert bzw. normalisiert.

Zu dem Text aus Heindorfs Ausgabe sind im Apparat die für die verschiedenen Stufen der Übersetzung einschlägigen Varianten aus den Vorgängereditionen sowie besonders die aus der Edition von Bekker (1817) mitgeteilt, die die Vorlage für die Überarbeitung der Übersetzung für die zweite Auflage ist. Außerdem sind Konjekturen Schleier-

275 S. u. S. $29 \mathrm{~W}^{1}$ Anm. 1 mit App. S. 
machers vermerkt, auch wenn sie bereits in Heindorfs Ausgabe gedruckt sind, da Schleiermacher bei der Erarbeitung der (handschriftlichen) Übersetzung noch nicht die gedruckte Ausgabe, sondern Heindorfs Handschrift bzw. Material und Vorarbeiten benutzt hat. Auf Auslassungen in den Übersetzungen gegenüber dem griechischen Text wird nur in besonderen Fällen im Apparat zum griechischen Text hingewiesen. Im Übrigen sind sie aus dem synoptischen Nebeneinander der Texte zu ersehen.

Handschriftliches Material zum Gorgias ist nicht erhalten, so dass die zweite Spalte leer bleibt.

Die gedruckten Texte der 1. und 2. Auflage (Spalte 3 und 4) sind jeweils nach dem Wortlaut ibrer Vorlage wiedergegeben. Die dort auf dem äußeren Rand aufgefübrten Stephanusseitenzablen sind in der Edition nicht mitgeführt, da sie zum griechischen Text links am Rand erscheinen. Die zweite Auflage hat im Gegensatz zur ersten durchgehend Kolumnentitel, die in der Edition weggelassen sind. Die Varianten zwischen beiden Auflagen sind nicht eigens in den Apparaten angegeben, da sie aus der synoptischen Präsentation ersichtlich sind. Allerdings ist immer $d a$, wo die Ursache einer Veränderung zur zweiten Auflage hin greifbar ist, diese im Sachapparat nachgewiesen.

\section{B. Theaitetos}

Der griechische Text (Spalte 1) ist aus der Ausgabe von Heindorf (1805) gegeben, deren verschiedene Entstehungsstufen Schleiermacher benutzt hat, deren Erscheinen im Oktober 1805 jedoch für die Erarbeitung der Übersetzung zu spät kam. ${ }^{276}$ Zur Textgestalt gilt das oben zu A. Gorgias Gesagte.

$\mathrm{Zu}$ dem Text aus Heindorfs Ausgabe sind im Apparat die für die verschiedenen Stufen der Übersetzung einschlägigen Varianten aus den Vorgängereditionen mitgeteilt, besonders aus der Editio Bipontina (1782), die die Textgrundlage der Lesung mit Heindorf 1802 und der aus dieser resultierenden handschriftlichen Noten ist, sowie aus der Edition von Bekker (1817), die die Vorlage für die Überarbeitung der Übersetzung für die zweite Auflage ist. Außerdem sind Konjekturen Schleiermachers vermerkt, auch wenn sie bereits in Heindorfs Ausgabe gedruckt sind, da Schleiermacher bei der Erarbeitung der (handschriftlichen) Übersetzung noch nicht die fertige und gedruckte

276 S. u. S. 453 Spalte 3 App. S. 
Ausgabe, sondern nur Heindorfs bzw. gemeinsame Vorarbeiten benutzt hat. ${ }^{277}$ Aus diesem Grund sind teilweise auch erst bei der Überarbeitung der Übersetzung für die zweite Auflage Korrekturen und Änderungen nach der Heindorfschen Ausgabe gemacht worden. Auf Auslassungen in den Übersetzungen gegenüber dem griechischen Text wird nur in besonderen Fällen im Apparat zum griechischen Text hingewiesen. Im Übrigen sind sie aus dem synoptischen Nebeneinander der Texte zu ersehen.

Die Handschriften (Spalte 2) stammen aus der Zeit der Vorbereitung für die gemeinsam mit F. Schlegel geplante, aber gescheiterte Publikation im Verlag Friedrich Frommann. ${ }^{278}$ Es existieren nur handschriftliche Vorarbeiten. Ediert sind a) handschriftliche Noten aus einer bzw. zwei Lesungen mit Heindorf als Vorarbeiten zur Übersetzung. Die einzelnen Noten sind mit den Seitenzahlen der Ed.Zweibrücken (Bipontina) auf die Stellen des griechischen Textes bezogen. Diese Seitenangaben sind in der Edition weggelassen und durch die Stephanusseitenzahlen mit dem Zusatz der Seitenzeile in dieser Edition ersetzt.

b) Gleichsam als sekundärer Apparat von den eigenhändigen Noten Schleiermachers abgesetzt, werden - ergänzend $z u$ diesen Noten - Noten Heindorfs in Briefen an Schleiermacher, die den gemeinsamen Prozess der Lektüre und Textkonstitution auch nach Schleiermachers Umzug nach Stolp dokumentieren, aus KGA V, ggf. nach der Handschrift korrigiert, wiedergegeben. Der Bezug wird analog zu Schleiermachers Noten hergestellt. Der jeweilige Brief und die Textgrundlage sind zur Stelle angegeben. Die Noten Heindorfs erhalten keine eigenen Apparate und keine Zeilenzählung am Rand. Zitierte Literatur wird als Material, das Schleiermacher zumindest auf diesem Wege bekannt war, im Apparat $S$ unter der Sigle Heind. nachgewiesen. Ebenda ist bei textkritischen Noten auf den Apparat zum griechischen Text verwiesen, da diese Noten eine Vorarbeit und Vorstufe zu Heindorfs Edition (1805) sind.

277 Vgl. die handschriftlichen Noten in SN 166 sowie in einzelnen Briefen (ediert in Spalte 2). Im Übrigen gilt wohl analog das, was Schleiermacher zu seiner Übersetzung des Parmenides angemerkt hat: „Dieses Gespräch haben einmal mein Freund Heindorf und ich so gemeinschaftlich durchgearbeitet, daß von vielen Verbesserungen des Textes sich nicht mehr entscheiden läßt, wem sie oder wieviel davon Jedem zukommen." (Platons Werke, von F. Schleiermacher, Ersten Theiles zweiter Band, Berlin ${ }^{1} 1805$, S. 401; vgl. oben Anm. 148).

278 S. o. S. XLV-XLVIII und S. XXII sowie KGA IV/3, S. XV-XXVII. 
$\mathrm{Zu}$ den gedruckten Texten der 1. und 2. Auflage (Spalte 3 und 4) gilt das oben zu A. Gorgias Gesagte.

\section{Menon}

Der griechische Text (Spalte 1) ist aus der von Schleiermacher benutzten Zweibrücker Ausgabe (Bipontina) von 1783 gegeben. Die dort am Rand mitgeführte Stephanusseitenzählung wird auf dem Außenrand angegeben. Nicht angegeben ist die Seitenzählung der Zweibrücker Ausgabe. Die Besonderheiten in der Orthographie, Akzentsetzung und Interpunktion sind in der Regel beibehalten.

$\mathrm{Zu}$ dem Text aus der Zweibrücker Ausgabe sind im Apparat die für die verschiedenen Stufen der Übersetzung einschlägigen Varianten aus den Vorgängereditionen und der Edition von Biester (1780; 21790) sowie die aus der Edition von Bekker (1817) mitgeteilt, die für die Überarbeitung der Übersetzung für die zweite Auflage besonders relevant sind. Auf Auslassungen in den Übersetzungen gegenüber dem griechischen Text wird nur in besonderen Fällen im Apparat zum griechischen Text hingewiesen. Im Übrigen sind sie aus dem synoptischen Nebeneinander der Texte zu ersehen.

Die Handschriften (Spalte 2) bieten sehr unterschiedliches Material. Die eigenhändigen Handschriften stammen aus der Zeit der Vorbereitung für die gemeinsam mit F. Schlegel geplante, aber gescheiterte Publikation im Verlag Friedrich Frommann. ${ }^{279}$ Es existieren nur handschriftliche Vorarbeiten. Ediert sind a) ein Exzerpt aus Wolfs Platonischen Heften und b) handschriftliche Noten als Vorarbeiten zur Übersetzung. In beiden Handschriften sind die einzelnen Notizen mit den Seitenzahlen der Ed.Zweibrücken (Bipontina) auf die Stellen des griechischen Textes bezogen. Diese Seitenangaben sind in der Edition weggelassen und durch die Stephanusseitenzahlen mit dem Zusatz der Seitenzeile in dieser Edition ersetzt.

c) Gleichsam als sekundärer Apparat von den eigenhändigen Exzerpten und Noten Schleiermachers abgesetzt, werden Noten Buttmanns in Briefen an Schleiermacher aus KGA V, ggf. nach der Handschrift korrigiert, wiedergegeben. Erstmals aus der Handschrift ediert werden Noten Heindorfs, die dem Brief von Buttmann als Beilage hinzugefügt waren. Die Noten Buttmanns und Heindorfs stammen aus der Zeit der Vorbereitung bzw. endgültigen Überarbeitung der Übersetzung für den Druck bei Georg Andreas Reimer

279 S. o. S. LIII-LV und S. XXIII-XXIV sowie KGA IV/3, S. XV-XXVII. 
(1805).280 Der Bezug wird analog zu Schleiermachers Noten hergestellt. Der jeweilige Brief und die Textgrundlage sind zur Stelle angegeben.

Da die Noten Buttmanns und Heindorfs (1805) aus einem anderen Arbeitszusammenhang stammen als die eigenhändigen Exzerpte und Notizen Schleiermachers (1802), erhalten sie eigene (mit Buttm. und Heind. bezeichnete) Apparate, jedoch keine Zeilenzählung am Rand.

d) Im Apparat $S$ zu der Note Buttmanns zur mathematischen Stelle im Menon 281 ist eine Erklärung dieser Stelle von August Boeckh, die Schleiermacher übersandt worden war (SN 514/2), erstmals aus der Handschrift ediert. Die eigenhändige Skizze Boeckhs ist als Abb. 2 wiedergegeben.

Zu den gedruckten Texten der 1. und 2. Auflage (Spalte 3 und Spalte 4) gilt das oben zu A. Gorgias Gesagte.

\section{Euthydemos}

Der griechische Text (Spalte 1) ist aus der von Schleiermacher im (handschriftlichen) Entwurf benutzten Ausgabe von Heindorf gegeben, die 1806 erst nach Schleiermachers 1. Auflage erschienen ist. ${ }^{282}$ Im Übrigen gilt das oben zu A. Gorgias Gesagte.

Die Handschrift (Spalte 2) stammt aus der Zeit der Vorbereitung für die gemeinsam mit F. Schlegel geplante, aber gescheiterte Publikation im Verlag Friedrich Frommann. ${ }^{283}$ Es existieren nur handschriftliche Noten als Vorarbeiten zur Übersetzung. Die einzelnen Noten sind mit den Seitenzahlen der Ed.Zweibrücken (Bipontina) auf die Stellen des griechischen Textes bezogen. Diese Seitenangaben sind in der Edition weggelassen und durch die Stephanusseitenzahlen mit dem Zusatz der Seitenzeile in dieser Edition ersetzt.

$\mathrm{Zu}$ den gedruckten Texten der 1. und 2. Auflage (Spalte 3 und Spalte 4) gilt das oben zu A. Gorgias Gesagte.

280 S. o. S. LV-LX und S. XXVII-XXVIII sowie KGA IV/3, S. XXVII-XXXVI.

281 S. u. S. 964.

282 Vgl. unten S. $1057 W^{1}$ Anm. 1 mit App. S.

283 S. o. S. LX-LXI sowie KGA IV/3, S. XV-XXVII. 


\section{Danksagung}

Auch der vorliegende Band ist das Produkt der Arbeit Vieler, obne deren Zusammenarbeit er nicht hätte zustande kommen können. Bei den Vorarbeiten haben Lukas Schellhorn, Laura Schmidt und Marvin Harms als studentische oder wissenschaftliche Hilfskräfte, später auch zeitweise Sarah-Christin Schröder und Lasse Felgendreher vielfältige Arbeiten geleistet; über den gesamten Zeitraum haben die zentrale Editionsarbeit - und nicht zuletzt die Endphase mit den Korrekturen und der Erstellung der Indices - Alena Maaß und Jens Gehri mit unermüdlichem Einsatz und großer Gewissenhaftigkeit unterstützt.

Das Archiv der Berlin-Brandenburgischen Akademie der Wissenschaften hat wiederum bereitwillig Zugang zu den handschriftlichen Archivalien im Schleiermacher-Nachlass gewährt, wichtige Handschriften als Digitalisate zur Verfügung gestellt und die Publikationserlaubnisse für Text und Abbildung erteilt. In der Handschriftenabteilung der Staatsbibliothek zu Berlin - Preußischer Kulturbesitz hat uns Ralf Breslau die Sichtung des umfangreichen Nachlasses von Friedrich August Wolf ermöglicht.

Die technische Realisierung der Edition erfolgte mit dem Computerprogramm "Classical Text Editor" (CTE). Sein Entwickler Stefan Hagel (Wien) löste hilfsbereit manch ein projektspezifisches Problem. Sachliche oder bibliographische Unterstützung leistete mehrfach die Schleiermacher-Forschungsstelle in Kiel.

Finanziell wurde das Projekt großzügig aus Mitteln der Fritz Thyssen Stiftung gefördert. Das Institut für Klassische Altertumskunde der Christian Albrechts Universität zu Kiel hat dem Projekt weiterhin Räumlichkeiten zur Verfügung gestellt. Die administrative Seite des Projektes betreute stets umsichtig und zuverlässig Gabriela Wulff-Döbber.

Der Verlag de Gruyter, namentlich Florian Ruppenstein und Albrecht Döhnert, hat uns bei der schwierigen Gestaltung des Bandes stets hilfsbereit beraten und unterstützt.

Allen genannten Personen und Institutionen danken wir für ibre Mitwirkung, Hilfe und Unterstützung auf das Herzlichste. Ohne sie wäre die Fertigstellung eines so „starken" 284 Bandes nicht möglich gewesen.

Lutz Käppel Johanna Loehr Kiel, am vierten Advent 2019

284 Vgl. oben S. XV das Motto der Einleitung. 